
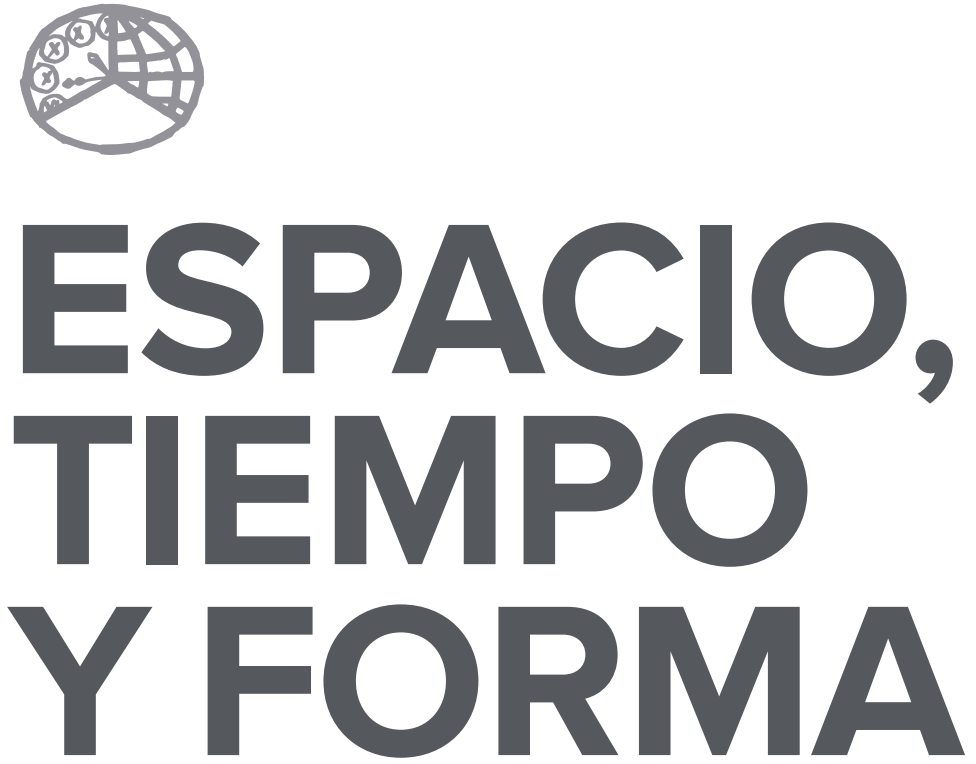

AÑO 2018

ISSN 0214-9745

E-ISSN 2340-1362

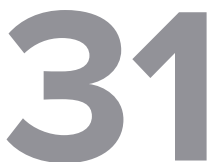

SERIE III HISTORIA MEDIEVAL

REVISTA DE LA FACULTAD DE GEOGRAFÍA E HISTORIA 



\section{ARTÍCULOS · ARTICLES}





\title{
CIEN AÑOS DE MONEDA EN \\ CASTILLA (1172-1268). EL SIGLO \\ DEL MARAVEDÍ DE ORO
}

\section{ONE HUNDRED YEARS OF CURRENCY \\ IN CASTILE (1172-1268). THE CENTURY OF THE GOLD MARAVEDI}

\author{
Gonzalo Oliva Manso'
}

Recepción: 2017/05/7 · Comunicación de observaciones de evaluadores: 2017/9.12 .

Aceptación: 2017.11.6

DOI: http://dx.doi.org/10.5944/etfiii.31.2018.18968

\begin{abstract}
Resumen
A lo largo del siglo que abarca nuestro trabajo estudiamos primero la documentación disponible para a continuación calcular matemáticamente las equivalencias que regían el sistema monetario. El cambio entre el maravedí de oro y los dineros de vellón estuvo sometido a constantes tensiones debidas a la creciente tendencia del oro a apreciarse respecto a la plata y a las manipulaciones unilaterales de los dineros por parte del rey. El cambio oficial no reflejaba estos cambios con la suficiente rapidez y los actores económicos empezaron a fijar sus propias condiciones en los negocios privados. Las distorsiones producidas en la economía por el intervencionismo regio fueron combatidas con más intrusión con la imposición de tasas de precios y prohibiciones a la exportación. Al final de nuestro período de estudio el maravedí alfonsí deja paso a la dobla como moneda de oro de referencia mientras los dineros de vellón inician un período de devaluaciones continuas.
\end{abstract}

\section{Palabras clave}

Sistema monetario; Castilla; ajuste monetario; devaluación; maravedí; sueldo; burgalés; pepión.

1. Doctor en Geografía e Historia y en Derecho. Universidad Rey Juan Carlos (profesor externo). C.e.: concejodemadrid@gmail.com 


\begin{abstract}
Firstly, we will analyze the documentation available, covering a time span of over a century, to calculate mathematically the rates within the monetary system on the basis of these sources. The exchange rate between the gold maravedi and the dinero de vellón was subjected to constant stresses due to the growing tendency of gold to appreciate with respect to silver and the unilateral manipulation of the value of the dinero by the king. The official exchange rate did not reflect these changes fast enough, and economic actors began to set their own conditions in their private transactions. The distortion produced in the economy by royal interventionism was fought with further encroachment through the implementation of price rates and export bans. At the end of our period of study, the maravedi alfonsí gave way to the dobla as the gold coin of reference, while the dinero de vellón began a period of constant devaluation.
\end{abstract}

\title{
Keywords
}

Monetary System; Castile; Monetary Adjustment; Devaluation; Maravedí; Sueldo; Burgalés; Pepión. 


\section{INTRODUCCIÓN}

En un trabajo publicado recientemente ${ }^{2}$ se ha ofrecido una novedosa explicación sobre la naturaleza del mencal o mejor dicho las varias naturalezas que presentó a lo largo de su azarosa existencia siempre en íntima relación con el oro que fue dejando un tanto de lado durante el reinado de Fernando III al ir ganando terreno su condición de moneda de cuenta. El objetivo de esta investigación consistirá en relacionar los áureos o maravedís de oro, en sus múltiples variantes, con la cambiante moneda de vellón emitida por el reino castellano y en menor medida con la moneda de plata casi pura, mayoritariamente almohade pero también castellana emitida por Fernando Ill y Alfonso X.

La relación entre ambos numerarios se convirtió en una cuestión de suma importancia a partir del siglo xı ya que la conquista de Toledo supuso la ruptura de la uniformidad monetaria existente hasta ese momento. Desde entonces Castilla se dividió en dos grandes áreas caracterizadas cada una de ellas por un tipo monetario y un área de comercio principal diferentes. Las tierras al norte del Duero vertebradas por el Camino de Santiago utilizaron mayoritariamente el vellón, casi exclusivo en Galicia, derivada del flujo de bienes y personas desde Europa. Al sur del río y hasta la frontera con al-Ándalus primó el uso del oro aportado por el comercio, el botín y las parias abonadas por los reinos de taifas ${ }^{3}$. El nexo de unión se reflejó en el establecimiento de una equivalencia variable en el tiempo entre el maravedí de oro y los dineros de vellón ${ }^{4}$ en una tendencia que de forma pausada y constante fue incrementando el número de estos que eran necesarios para cambiarse por una moneda áurea5.

El marco temporal que nos marcamos abarca el período II72-I268 y se corresponde con el período de circulación del maravedí alfonsí de oro. Nos movemos entre su obligado nacimiento en tiempos de Alfonso VIII como respuesta a la escasez de numerario áureo tras la caída de la taifa murciana del rey Lobo y su desaparición con el primero de los grandes cambios que Alfonso X introdujo en el sistema monetario. Al final de nuestro período de estudio el maravedí quedó ya únicamente como una moneda de cuenta iniciando una prolongada y constante

\footnotetext{
2. Oliva MANSO, Gonzalo: «Enigmas monetarios en el derecho local. Los mencales y maravedís en los fueros castellanos», Revista General de Información y Documentación, 26-1 (2016), pp. 313-340.

3. Gautier DalChÉ, Jean: «Le rôle de la reconquête de Tolède dans l'histoire monetaire de la Castille (1085-1174)», en Estudios sobre Alfonso VI y la reconquista de Toledo. Actas del II Congreso Internacional de Estudios Mozárabes (Toledo, 20-26 Mayo 1985), vol. II, Toledo, Instituto de Estudios Visigótico-Mozárabes, 1988, pp. 613-622; LADERo QUESADA, Miguel Ángel: «Monedas y políticas monetarias en la Corona de Castilla (siglos XIII a XV)», Moneda y monedas en la Europa medieval (siglos XII-XV): XXVI Semana de Estudios Medievales, Estella, 19 a 23 de julio de 1999, Pamplona, Gobierno de Navarra, 2000, pp. 139-140.

4. El maravedí de oro tenía su réplica en un maravedí de cuenta formado por monedas de vellón de modo que la cantidad de oro contenida en un el primero podía cambiarse por la cantidad de plata aleada en esas monedas de vellón. 5. La primera noticia que tenemos habla del cambio de un maravedí de oro por cuatro sueldos 048 dineros de vellón y es de 1117 (FLórez, Enrique (ed.): «Anales Toledanos II», España Sagrada, vol. XXIII, Madrid, Imprenta de D. Gabriel Ramírez, 1767, pp. 401-409).
} 
cuesta abajo que la llevó a convertirse en la Baja Edad Media en un sinónimo de moneda de baja calidad.

En este poco más de un siglo que estudiamos el modelo monetario se presenta bastante estable con unos cambios oficiales limitados por el pago del servicio de la moneda forera que ofrecían las cortes al rey a cambio de no manejar a su antojo el sistema monetario. Aun así, la situación podía irse de las manos a los agentes políticos y económicos. Las fluctuaciones en la oferta y demanda de los metales preciosos afectaban a los tipos de cambios de las monedas y aunque bastante estables cuando se producía alguna alteración se tardaba un tiempo en tomar medidas para reequilibrar el sistema. Por otro lado, estaban las decisiones tomadas por los gobernantes, algunas pactadas, la mayoría discrecionales, pero siempre coyunturales y nacidas con el único objetivo de conseguir unos fondos siempre escasos. Las apremiantes necesidades de la monarquía llevaban a la emisión subrepticia de partidas de monedas con menor contenido en metal precioso ${ }^{6}$. La solución pasaba siempre por la fijación de cambios extraoficiales que reflejaran el valor real de las monedas.

\section{EL MARAVEDÍ ALFONSÍ Y LOS CINCO SUELDOS (1172-1187)}

El primer modelo monetario que estudiamos no presenta más novedad que el cambio de la moneda de oro que siendo antes el maravedí almorávide perpetuado por las distintas taifas es ahora adoptado por el reino castellano al verse obligado a acuñar su propia moneda forzado por las circunstancias ya comentadas. Se siguen los parámetros anteriores en lo que concierne a su aspecto externo y a su fineza sin más cambios que los obligados en las leyendas por la propia personali-

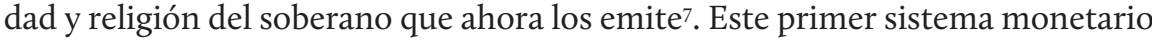
se articula en torno a las siguientes equivalencias ${ }^{8}$ :

6. Todesca rechaza esta posibilidad y aboga por el mantenimiento del valor del vellón dejando a las fluctuaciones del valor del oro como única causa de las tensiones monetarias (TODESCA, James J.: «Money of account and circulating coins in Castile-Leon c. 1085-1300», Problems of Medieval Coinage in the Iberian Area, 3 (1988), p. 281).

7. La descripción de estas monedas áureas así como otras aludidas en el trabajo pueden consultarse en Francisco OLmos, José María de: «El maravedí de oro de Alfonso VIII: un mensaje cristiano escrito en árabe», Revista General de Información y Documentación, 8.1 (1998), pp. 283-301.

8. Los resultados obtenidos por Collantes no coinciden en absoluto con los que se van a ver a lo largo del trabajo. La razón estriba en que asignó un número de dineros a cada dinar / maravedí erróneo al utilizar como base de los cálculos un mencal como reunión de 18 dineros siguiendo los planteamientos hechos por un investigador del prestigio de Beltrán (Collantes VIDaL, Esteban: «Monedas de Alfonso VIII y sus problemas», Acta Numismática, 3 (1973), pp. 115-116). 
Un maravedí alfonsí $=3,84 \mathrm{~g}$ de oro ${ }^{9}$

Cambio oro $/$ plata $=6,607 \sim 62 / 3$

Un maravedí alfonsí $=25,6 \mathrm{~g}$ de plata

Un maravedí alfonsí $=5$ sueldos $=60$ dineros

Un dinero $=0,427 \mathrm{~g}$ de plata

Un marco de plata $=9$ maravedís de cuenta
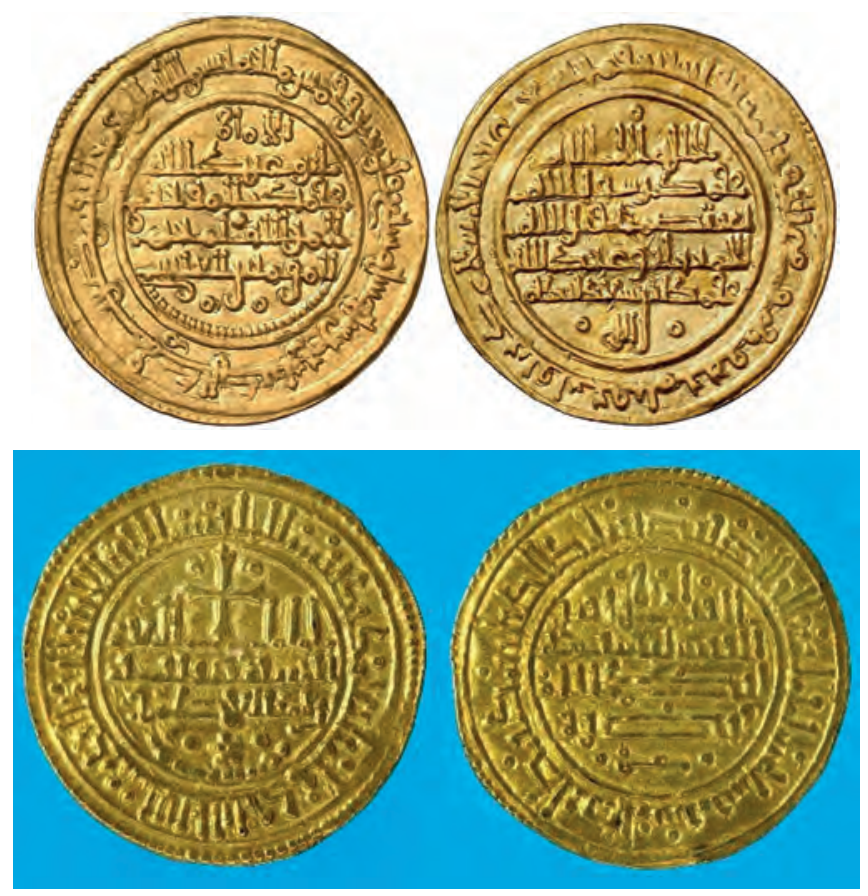

FIGURA 1. DINAR SAADÍ DE MUHAMMAD IBN MARDANIS (1152-3) Y MARAVEDÍ ALFONSÍ DE ALFONSO VIII (1181). Fuente: Áureo \& Calicó y Museo Arqueológico Nacional.

El primer documento de relevancia que se puede utilizar detalla la compra en II78 por parte de don Miguel, obispo de Coímbra, de una determinada cantidad de plata sin amonedar por su correspondiente precio en monedas de oro. Se acuerda el pago de «LXVIII morabetinos auri» por 7,5 marcos de plata. De donde sale que cada marco vendría a valer 9,067 maravedís de oro con lo que la relación oro / plata

\footnotetext{
9. El peso del marco de plata $-230,0465 \mathrm{~g}$ de plata- y el contenido en oro de los maravedís que se utilizan en este y siguientes cuadros proceden del trabajo de OlIVA MANSO (op. cit., p. 333):

Maravedí Peso (G) Lre

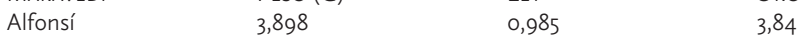

Alfonsí nuevo (A) $\quad 3,898 \quad 0,875 \quad 3,411$

$\begin{array}{llll}\text { Alfonsí nuevo (B) } & 3,898 & 0,8 & 3,118\end{array}$

$\begin{array}{llll}\text { Chico o parvo } & 2,339 & 0,989 & 2,313\end{array}$
} 
era en esos momentos de $6 \frac{2}{3}$. La utilización de un documento portugués, en este caso, no distorsiona nuestras conclusiones ya que la relación de cambio entre los dos metales preciosos no viene dada por una decisión particular del poder político sino por la coyuntura económica internacional por lo que su valor es semejante entre los países de una misma área.

La división del maravedí de cuenta en cinco sueldos o sesenta dineros que hemos utilizado está documentada en un escrito toledano de I226 por el que se llega a una concordia entre el gremio de «conejeros», cazadores de esta especie animal, y el canónigo don Alfonso Meléndez sobre el paso y estancia por sus tierras. El arreglo está motivado por el incumplimiento que aquellos han hecho de un acuerdo anterior de II64 en el que se establecía para estos casos: «como multa la caza que lleva más sesenta dineros de a cinco sueldos el mizcal» ${ }^{\mathrm{IO}}$. Esta misma subdivisión está presente en el fuero de Santa María de Cortes (II82, enero): «Item omnes soldi qui pectati fuerint per calumnia vel per coto V. computentur pro morbetin vno» ${ }^{\mathrm{II}}$. De igual manera el vecino reino de León parece seguir los mismos patrones que en Castilla $^{\mathrm{I} 2}$, quizás heredados de tiempos anteriores cuando ambos reinos compartían un mismo gobierno durante el reinado de Alfonso VIl. Documentos gallegos de los años II86, II90 y I203 nos dan un valor por «marcha argenti canonice» de 45 sueldos, dos de ellos, y $45^{1 / 2}$ sueldos, el restante ${ }^{13}$.

Aunque sin soporte documental, algunos autores ${ }^{14}$ se hacen eco de una referencia muy anterior, de II34 que no puede darse por válida pues su origen es extrapeninsular, francés por más señas y más concretamente de Cahors. Se trata de una donación a los clérigos de San Antonio quienes recibían todos los años, la víspera de su festividad, un maravedí de cinco sueldos de valor -«debent reddere per unumquemque annum clericis beati Antonini, præsentibus \& futuris, in die festivitatis ejus, unum morabetinum quinque solidos bene valentem ${ }^{15}-$.

Un dinero con estas características podría tratarse del denominado por Roma Valdés dinero burgalés primitivo de Alfonso ${ }^{16}$. Se trata de una pieza bien conservada

10. González Palencia, Ángel: Los mozárabes de Toledo en los siglos XII y XIII, vol. III, Madrid, Instituto de Valencia de Don Juan, 1928-1930, doc. 956.

11. García López, Juan Catalina: La Alcarria en los dos primeros siglos de su reconquista. Discursos leídos ante la Real academia de la Historia en la recepción del Excmo. Sr. D... en 27 de mayo de 1894, Madrid, El Progreso, 1894, doc. 3.

12. González, Julio: Alfonso IX, Madrid, CSIC. Instituto Jerónimo Zurita, 1944, p. 298.

13. Pérez Rodríguez, Francisco Javier: Os documentos do Tombo de Toxos Outos, Santiago de Compostela, Consello da Cultura Galega, Sección de Patrimonio Histórico, 2004, docs. 274 y 289; LOSCERTALES de García de VALDEAVELLANO, Pilar: Tumbos del Monasterio de Sobrado de los Monjes, vol. 2, Madrid, Dirección General del Patrimonio Artístico y Cultural, Archivo Histórico Nacional, 1976, doc. 364.

14. Gil Farrés, Octavio: Historia de la moneda española, Madrid, Diana, 1959, p. 317; LADERo Quesada, Miguel Ángel: «Monedas y políticas...», pp. 140 y 142; ROMÁ VALDÉs, Antonio: Moneda y sistemas monetarios en Castilla y en León durante la Edad Media (1087-1366), Barcelona, Asociación Numismática Española, 2000, p. 53; EsPAÑA, León de: Sistemas monetarios peninsulares. La acuñación de moneda cristiana tras la invasión de los musulmanes hasta el siglo XV, Madrid, Fundación León de España, 2002, pp. 51-52.

15. SAINTE-MARTHE, Denis de: Gallia Christiana, in provincias ecclesiasticas distributa: qua series et historia Archiepiscoporum, episcoporum et abbatum Franciae vicinarumque ditionum..., vol. 1, París, J-B Coignard, 1715, pag. 46.

16. Roma VALDÉs, Antonio: Moneda y sistemas..., pp. 263-264. 
de 0,73 g. con una proporción de plata del $67,7 \%$, lo que hace un contenido de o,49 g. de metal precioso, ahora bien, él mismo presenta algunas dudas:

Asumiendo que el peso puede estar en $0,89 \mathrm{~g}$, y suponiendo que existe un exceso en el análisis, parece difícil pensar que su proporción de plata sea inferior al 50 por 100, con lo que el resultado debe exceder de $0,45 \mathrm{~g}$ de plata. Aun así, es posible que ese peso esté estimado a la baja y que exceda de 1 gramo, de suerte que el ideal de plata estuviese en $0,54 \mathrm{~g}$ de plata ${ }^{17}$.

De acuerdo con los números que se deducen del sistema de equivalencias se comprueba como la primera reflexión de Roma Valdés sería la correcta ya que sus 0,89 g. se acercan a los 0,846 g. reales que le corresponderían a una moneda como la que hemos calculado y que estaría compuesta al $50 \%$ por plata y cobre ${ }^{\mathrm{I} 8}$.

Tiene razón Roma Valdés al presentar él mismo estas objeciones, la metalurgia en la Medioevo estaba lejos de ser una técnica exacta y pueden darse grandes variaciones entre monedas de una misma emisión lo que sólo puede salvarse en el momento actual si se cuenta con análisis metalográficos de una cantidad apreciable de monedas de cada una de las emisiones. A este respecto son significativas las normas dadas en I297 por Fernando IV para la acuñación de moneda de vellón en Lorca y en las que se admite un amplio rango de variación en cuanto a la ley individual de los dineros. En este primer ordenamiento sobre monedas correspondiente al ámbito castellano-leonés que nos ha llegado aparecen unas prescripciones técnicas $^{19}$ que establecen que del marco de metal aleado han de obtenerse 264 dineros (22 sueldos) cada uno de los cuales pesaría o'87I gramos, peso que viene a ser sustancialmente el mismo que el de los dineros de Alfonso VIII, y siendo su ley de dos dineros contendrían una cantidad de plata de o'I45 gramos. Ahora bien, se admitían ciertas desviaciones sobre el valor teórico y así dentro de cada marco podían darse hasta diez dineros «febles» con un mínimo de o'i28 gramos de plata, o diez dineros «fuertes» con hasta o'I68 gramos; más aún, se aceptaba incluso que uno de los dineros «febles» y otro de los «fuertes» superaran estos límites. Manejando estos márgenes resulta muy complicado hacer

\footnotetext{
17. Ibidem.

18. Un nuevo trabajo realizado recientemente por Roma Valdés analiza dos dineros burgaleses de una supuesta emisión de 1195. En esta ocasión tras el análisis metalográfico realizado no se dan pesos, solo las proporciones entre los distintos elementos componentes de las piezas, con el resultado de un contenido en plata cercano al 46\% (RomA VALDÉS, Antonio: Composición metálica de las monedas leonesas y castellanas de la Edad Media, Santiago de Compostela, A. Roma, 2010, p. 15).

19. «Que la moneda que sea a dos dineros de ley emblanquida argent fino et a veynte et dos sueldos en prietos de talla el marco, et que los dineros mas fuertes sean a dize nueue sueldos de talla el marco et los dineros mas febles que sean a veynte et çinco sueldos de talla el marco. Et si mester fuere que puedan reçebir en cada marco diez dineros fuertes de dize nueue sueldos de talla el marco, et diez dineros febles a veynte et çinco sueldos de talla el marco, pero si acaesçiera que aya en el marco vn dinero fuerte mas de dize nueue sueldos de talla el marca et otro feble mas de veynte et çinco sueldos el marco que passe et non se detenga la obra por ello, et lo al que sea reçeuido comunalmente, asi que venga todo en vno a veynte et dos sueldos en prietos de talla el marco» (TORRES FonTES, Juan: Documentos de Fernando IV, Murcia, Academia Alfonso X el Sabio-CSIC, 1980, doc. XXII). Pueden consultarse también las ordenanzas correspondientes a la emisión de cornados de Alfonso XI de 1334 donde se admiten unas divergencias similares (VEAS Arteseros, Francisco de Asís: Documentos de Alfonso XI, Murcia, Academia Alfonso X el Sabio-CSIC, 1997, doc. CCLVIII).
} 
cualquier afirmación de forma rotunda si no disponemos de un análisis efectuado sobre un número sustancial de monedas que eliminen los valores extremos y se acomoden a la media real.

\section{EL MARAVEDÍ ALFONSÍ NUEVO (A) Y LOS CINCO SUELDOS (1187-1217)}

En II87 se produjo una alteración considerable en el sistema monetario castellano al hacerse oficial una nueva moneda de oro: el maravedí alfonsí nuevo $(\mathrm{A})^{20}$. Las equivalencias correspondientes para este nuevo sistema monetarios eran las siguientes:

Un maravedí alfonsí nuevo $(\mathrm{A})=3,4 \mathrm{II}$ g de oro

Cambio oro $/$ plata $=6 \frac{2}{3}$

Un maravedí alfonsí nuevo $(\mathrm{A})=22,738 \mathrm{~g}$ de plata

Un maravedí alfonsí nuevo $(\mathrm{A})=5$ sueldos $=60$ dineros

Un dinero $=0,379 \mathrm{~g}$ de plata

Un marco de plata $=$ Io $1 / 4$ maravedís de cuenta

No disponemos tampoco del tipo de cambio oro / plata existente en Castilla en esos momentos. Disponemos de algunos datos correspondientes al mundo musulmán del Mediterráneo occidental que vienen a coincidir o a ser muy cercanos al utilizado en el apartado anterior y que podemos aceptar sin excesivas reticencias pues las circunstancias político-económicas no varían sustancialmente respecto al período anterior y el oro africano continuó afluyendo hasta Europa por intermedio del imperio almohade sin interrupciones de relevancia. Es el caso de una noticia de Túnez con un cambio establecido en i: $6 \frac{1}{1} 2$ en los entornos del año

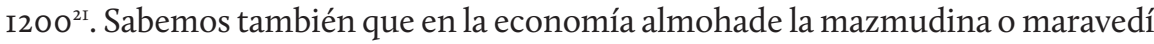
chico se cambiaba por Io dirhemes ${ }^{22}$, teniendo cada uno de estos últimos un peso de un tercio de la dobla ${ }^{23}$. No disponemos de análisis metalográficos por lo que

\footnotetext{
20. Oliva Manso, Gonzalo: op. cit., pp. 326-327.

21. Spufford, Peter: Dinero y moneda en la Europa medieval, Barcelona, Crítica, 1991, p. 224.

22. Beltrán Villagrasa, Pío: «Dos tesorillos de vellones ocultos en la primera época del reinado de Alfonso X», en Obra completa, vol. II, Zaragoza, Universidad de Zaragoza, 1972, p. 653 (trabajo publicado originalmente en Nvmisma, 68 (1964), pp. 55-79 y 69 (1964), pp. 7-20).

23. Medina Gómez, Antonio: Monedas hispano-musulmanas, Toledo, Instituto Provincial de Investigaciones y Estudios Toledanos, 1992, p. 396; IBRAHIM, Tawfiq: «Ponderales andalusíes», Nvmisma, 233 (1993), p. 58. Relación que continuaba en el período nazarí como figura en el Libro que aproxima y facilita al máximo el trabajo del aprendiz en el arte de medir superficies escrito entre 1281-1291 por Ibn al-Yayyab (VALLVÉ BERMEJO, Joaquín: «Notas de metrología hispano-árabe. III. Pesos y monedas», Al-Qantara, 5 (1984), pp. 147 y 159).
} 
hemos optado por asignarle a este dirhem una ley máxima del $99 \%$, ya vista en la Península en tiempos del emirato independiente ${ }^{24}$.

Peso: Una dobla de 4,678 $\mathrm{g}=3$ dirhemes de $\mathrm{I}, 559 \mathrm{~g}$

Valor: Una mazmudina de 2,313 $\mathrm{g}$ de oro = Io dirhemes de I,543 g de plata

Cambio oro $/$ plata $=6 \frac{2}{3}$

Igualmente seguimos manteniendo la subdivisión del maravedí de cuenta en 60 dineros burgaleses ${ }^{25}$. Como en el caso anterior carecemos de cita alguna que la indique expresamente, aunque existen otras que permiten deducir esta relación. Estos dineros calificados como burgaleses aparecen citados en la historiografía, concretamente en Jiménez de Rada y Alfonso X:

Historia de rebvs Hispaniae, cap. VIII, IV: «Cum enim essent ultramontani plusquam decem milia equitum et centum milia peditum, unicuique militi dabantur omni die $X X^{\text {ti }}$ solidi usuales, pediti uero $V^{e}$ solidi; mulieres, paruuli, debiles et ceteri ad bellum inepti non erant ab hac gracia alieni» ${ }^{26}$.

Primera Crónica General, cap. 1013: «Et el noble rey don Alffonsso cogiosse estonçes a su palaçio, et pensso et mando echar pregon por toda la hueste: que los caualleros todos que fuessen tomar quitaçiones, de xx sueldos de los burgaleses por el dia el cauallero, et cada peon $v$ sueldos dessa moneda uieia otrossí por el dia; et que esto les complirie el cada dia, fasta que Dios los aduxiesse daquello a que yuan» ${ }^{27}$.

A pie de página el editor de la obra alfonsina comenta como en algunos manuscritos existían notas marginales aclarando el valor de estos sueldos que se correspondían con ocho y dos maravedís respectivamente:

En mo. pone $E$ nota marginal en la que hay cortadas algunas letras por un encuadernador: que monta desta moneda ocho ... al de cauallo et al d... pi... IIII, nota que se incluye así en el texto de I: mo. que monta desta moneda ocho mrs. al de cauallo et al de pie dos mrs. dessa moneda ${ }^{28}$.

Ahora bien, según las equivalencias establecidas para el sistema monetario presente en I2I2 los cinco y los veinte sueldos se corresponden con uno y cuatro maravedís, no con dos y ocho como se transcribe en los manuscritos E e I. Sin embargo, hay que tener en cuenta que estos dos manuscritos están valorando las soldadas en función de la moneda del momento de redacción del texto. La Estoria de España comenzó a elaborarse en I270 cuando el numerario usual utilizado estaba recién modificado en las Cortes de Jerez de I268 donde se había establecido que el maravedí alfonsí valía dos maravedís de cuenta, por lo que si multiplicamos

24. Medina Gómez, Antonio: op. cit., p. 93.

25. Este es el tipo monetario casi exclusivo en algunos tesorillos de la época de Alfonso VIII -Otaza (Álava), Isar (Burgos) y Granada-y predominante en otros -Briviesca y Segovia- (HERNÁNDEZ, Francisco J.: Las rentas del rey. Sociedad y fisco en el reino castellano del siglo XIII, Madrid, Fundación Ramón Areces, 1993, P. CLXIII).

26. JIMÉnEz de RADA, Rodrigo: Historia de rebvs Hispaniae sive Historia gothica, Turnhout, Brepols Publishers, 2010.

27. Menéndez PIdal, Ramón (ed.): Primera Crónica General, Madrid, Bailly-Bailliere é Hijos, 1906.

28. Idem, p. 694. 
por dos las cantidades mencionadas en Jiménez de Rada inmediatamente desaparecen las incongruencias.

Hay que señalar, no obstante, que varios autores han propugnado la existencia de otras equivalencias para este período como seis $^{29}$, siete $^{30}$ y siete sueldos y medio ${ }^{31}$ por maravedí, aunque no aportan una cita concreta y solamente algún autor fundamenta sus afirmaciones. Es el caso de Todesca ${ }^{32}$ que deducía la existencia de la primera de ellas a partir de las sanciones que se imponían a quienes contravenían lo dispuesto en los diplomas emitidos por las cancillerías de Alfonso VIl y Alfonso VIII. Muy habitualmente cuantificadas en I.00o maravedís, pero también en alguna ocasión, durante el período II70-II89, en 6.000 sueldos $^{33}$. También la daba por buena Beltrán ${ }^{34}$ basándose en el fuero romanceado de Uclés (\# I5I): «Calumpnia de morabetino, de III mencales seiat; et calumpnia de V solidos, II mencales e medio» 35

Este dinero de $0,379 \mathrm{~g}$ contenía una cantidad de plata semejante a la que presentaban los dineros leoneses en $\mathrm{I} 208$ que era de $0,383 \mathrm{~g}^{36} \mathrm{y}$ con la muestra 3I estudiada por Roma Valdés cuyo contenido en plata es de $0,373 \mathrm{~g}^{37}$. Su puesta en circulación suponía una reducción de $0,054 \mathrm{~g}$ respecto a los dineros del período anterior y a pesar de ello ambos corrían con el mismo valor, lo que inmediatamente se tradujo en una creciente inflación cuando por un mismo bien, fuera una espada, una pieza de tela, un caballo o una heredad, hubo de darse un mayor número de dineros. Esta inflación llevaba inevitablemente a una serie de tensiones económicas que acababan finalmente por desestabilizar la economía llevando a una nueva devaluación ${ }^{38}$. Sobre esta devaluación especulaba en su momento Sánchez-Albornoz, aunque situándola en los entornos del año I200 ${ }^{39}$ cuando, tras la

\footnotetext{
29. Collantes VIDAL, Esteban: «Monedas de Alfonso VIII...», p. 114; Roma Valdés, Antonio: Moneda y sistemas monetarios..., p. 103.

30. Gautier DALCHÉ, Jean: «L'histoire monétaire de l'Espagne septentrionale et centrale du IX au XII siècles quelques réflexions sur divers problèmes», Anuario de Estudios Medievales, 6 (1969), p. 64.

31. Roma VALdés, Antonio: Moneda y sistemas monetarios..., pp. 103 y 168.

32. TODESCA, James J.: «The Monetary History of Castile-Leon (ca. 1100-1300) on light of the Bourgey hoard», American Numismatic Society Museum Notes, 33 (1988), p. 141.

33. González, Julio: El Reino de Castilla en la época de Alfonso VIII, Madrid, 1960, docs. 139, 160, 226 y 531.

34. Beltrán Villagrasa, Pío: «Dos tesorillos...», p. 654

35. Rivera Garretas, Milagros: La encomienda, el priorato y la villa de Uclés en la Edad Media (1174-1310). Formación de un señorío de la Orden de Santiago, Madrid-Barcelona, CSIC, 1985, doc. 236.

36. Calculado a partir de una relación entre el marco de plata y el sueldo de 1 a 50 . El documento en cuestión estaría depositado en el Tumbo del Monasterio de Sobrado de los Monjes II, fol. 132 y su existencia fue comunicada por GonZÁLEZ, Julio: Alfonso IX, Madrid, CSIC. Instituto Jerónimo Zurita, 1944, p. 298.

37. Roma VALdÉs, Antonio: Moneda y sistemas monetarios..., pp. 263-264. En otro trabajo Roma identifica como pepiones dos monedas insertas en un amplísimo rango temporal (1157-1252) con una proporción media de plata de 35,66\% (RomA VALDÉs, Antonio: Composición metálica..., p. 16).

38. Este proceso retroalimentado, un auténtico círculo vicioso de compleja solución fue ya comentado por Salvador de Moxó en su estudio de las congelaciones de precios de tiempos de Alfonso X («Época de Alfonso X», en JOVER Zamora, José M. ${ }^{a}$ (dir.), Historia de España, vol. 13-1, Madrid, Espasa Calpe, 1990, p. 154).

39. SÁNCHEZ-AlboRnOz, Claudio: «¿Devaluación monetaria en León y Castilla: al filo del 1200?», en Homenaje a Jaime Vicens Vives, vol. I, Barcelona, Universidad de Barcelona, Facultad de Filosofía y Letras, 1965, pp. 607-617.
} 
derrota de Alarcos (II95), las terribles razzias del bienio inmediato sometieron a Castilla a un desafío terrible.

Las medidas tomadas por Alfonso VIII no dejaban de ser meros parches para sortear la situación durante un tiempo. En las Cortes de Toledo de 1207 se trató de atajar la creciente inflación - «las cosas se uendien mas de so derecho, \& era uust[ro] gran danno»- limitando la salida del reino de determinados productos y estableciendo un estatuto de precios máximos - «coto en todas las cosas»-40 y que se convirtió en un recurso habitual desde entonces. La situación lejos de mejorar se volvió aún más complicada con la ofensiva almohade de i2 II que trajo consigo la caída del castillo de Salvatierra y la llamada de auxilio de Alfonso VIII a sus correligionarios europeos. La llegada de numerosos guerreros foráneos obligó a un esfuerzo supremo al reino castellano para pagar las soldadas ya comentadas. El clero llegó incluso a ceder la mitad de sus rentas de ese año y prácticamente todos los metales preciosos del reino acabaron en las casas de moneda transformados en dinero contante y sonante ${ }^{41}$. Sería en este momento o poco después a raíz de haberse quedado prácticamente en bancarrota cuando en opinión de Grasotti se produciría una nueva devaluación que se reflejaría de forma oficial en la bajada del tipo de cambio a 7,5 sueldos el maravedít2 ${ }^{2}$ pero que en este artículo trasladamos unos años hacia adelante.

Aunque a primera vista nuestras conclusiones discrepen de las ofrecidas por estos dos autores es posible integrar todas ellas en una visión unificadora. Tendríamos que ver entonces la segunda mitad del reinado de Alfonso VIII como un período difícil con una única devaluación oficial que continuó con otras emisiones de dineros depreciados con las que obtener recursos para sostener algunas de sus campañas más importantes como las de II95-II97, de existencia dudosa ante la falta de cualquier noticia contemporánea, y, sobre todo, la de I2I2 que obligó al pago de unas soldadas más que esplendidas y con su reflejo en la historiografía.

\section{EL MARAVEDÍ ALFONSÍ NUEVO (A) Y LOS $71 \frac{1}{2}$ SUELDOS (1217-1223)}

Con la entronización de Fernando Ill y el posicionamiento en la estructura gubernamental de una voluntad tan decidida como la de su madre Berenguela una

\footnotetext{
40. Hernández, Francisco J.: «Las Cortes de Toledo de 1207》, Las Cortes de Castilla y León en la Edad Media: actas de la primera etapa del Congreso Científico sobre la Historia de las Cortes de Castilla y León, Burgos 30 de septiembre a 3 de octubre de 1986, vol. I, Valladolid, Cortes de Castilla y León, 1988, p. 231; TODESCA, James J.: «The Monetary History...», p. 142. 41. «lbi tanta copia auri effundebatur cotidie, quam vix et nummeratores et ponderatores multitudinem denarriorum qui neccessarii erant ad expensas poterant numerare. Universus clerus regni Castelle, ad petitionem regni, medietatem omnium redituum suorum in eodem anno concesserant domino regi» (CHARLO BREA, Luis (ed.): Crónica latina de los Reyes de Castilla, Cádiz, Universidad de Cádiz, 1984, p. 35).

42. Grassotti, Hilda: «Sobre la moneda de Castilla en la época de don Rodrigo Jiménez de Rada», en Miscelánea de estudios sobre instituciones castellano-leonesas, Bilbao, Nájera, 1978, pp. 426-427.
} 
de sus primeras decisiones fue la de reorganizar el sistema monetario castellano establecido en i187. Suponiendo estables todos los parámetros oficiales del período anterior el nuevo sistema monetario se definió por las siguientes fórmulas.

Un maravedí alfonsí nuevo $(\mathrm{A})=3,4 \mathrm{II}$ gramos de oro

Cambio oro $/$ plata $=62 / 3$

Un maravedí alfonsí nuevo $(A)=22,738$ gramos de plata

Un maravedí alfonsí nuevo $(\mathrm{A})=7,5$ sueldos $=90$ dineros

Un dinero $=0,253$ gramos de plata

Un marco de plata $=$ IO $1 / 4$ maravedís de cuenta

La documentación nos habla de este nuevo dinero cuya relación con el maravedí ha variado, ya no se cambia por cinco sino por siete sueldos y medio. Esta moneda está atestiguada en el acuerdo que se firmó a finales de I2I7 para solventar las disputas que el rey castellano mantenía con su padre Alfonso IX de León y por el que se ajustaron treguas hasta la Pascua de Cuaresma del año siguiente. Por este tratado Fernando III se obligaba a entregar un total de 21.00o maravedís en moneda de vellón - «et morabetinos istos debent dare in denariis ad septem solidos et dimidium Burgalenses uel quindecim solidos de pepionibus pro morabetino» ${ }^{43}$-. El incumplimiento parcial del acuerdo motivó un nuevo acuerdo firmado en Toro el 26 de agosto de I2 I 8 - «undecim millia morabetinorum alfonsinorum uel septem solidos et dimidium Burgalensium aud quindecim solidos de pepionibus sue monete pro morabetino»-44. Una escritura palentina de 1222 confirma el carácter novedoso de estos burgaleses - «dineros de la moneda nueba que yo fiz labrar a nobenta dineros el maravedí»-45.

No queda claro por qué se optó por establecer dicho número en 90 dineros o 7,5 sueldos, ¿por qué no 84 dineros (siete sueldos) o 96 dineros (ocho sueldos) como en León? Un número entero y sobre todo este último ayudaría bastante a las gentes a la hora de hacer sus cálculos cuando se movían en fracciones de maravedí de tal manera que un medio, un tercio, un cuarto, un octavo o un doceavo de maravedí tenía su correspondencia en un número entero de dineros. Sin embargo, respecto a la anterior proporción sueldo-maravedí establecida en i:5, la nueva que ascendía a i:7,5 suponía un redondo 50\% de devaluación.

Su nacimiento tendría lugar en I2I7 en las mismas Cortes en las que se efectuó su coronación ${ }^{46}$. Los problemas económicos del nuevo rey eran muy importantes

\footnotetext{
43. González, Julio: Alfonso IX, doc. 352.

44. Idem, doc. 366.

45. González, Julio: Reinado y diplomas de Fernando III, vol. II, Córdoba, Publicaciones del Monte de Piedad y Caja de Ahorros de Córdoba, 1983, doc. 144.

46. Todesca formulaba la teoría de que sería en estas Cortes o en las celebradas en 1219 donde fue armado caballero y se formalizó su matrimonio con Beatriz de Suabia cuando se produciría este cambo monetario (TODESCA, James ).: «The Monetary History...», p. 152). Por su parte Sánchez-Albornoz se resistía a creer en un cambio monetario en estos
} 
y al decir de Jiménez de Rada no disponía de suficientes recursos con los que afianzar su posición frente a la rebelión nobiliaria encabezada por los Lara y a un padre-rival que acechaba desde el vecino reino de León. En esta tesitura de emergencia la forma más rápida para obtener numerario con el que pagar a sus tropas pasaba por acuñar moneda de forma inmediata utilizando todos los metales preciosos disponibles hasta el punto que doña Berenguela se desprendió de todos sus bienes ${ }^{47}$. Esta nueva moneda no podía acuñarse de forma unilateral so pena de perder el apoyo de nobles y concejos. No quedaba otra que consensuar el cambio, reconociendo el oficioso valor devaluado que había dejado Alfonso $\mathrm{VIII}^{48}$ y ofreciendo las consabidas promesas de estabilidad futura. En este sentido la crónica relata como los principales de Extremadura, Transierra y Toledo andaban reunidos y ante la llamada de la reina Berenguela acudieron a Valladolid donde ya estaban los nobles y caballeros castellanos y todos juntos reconocieron como rey a Fernando $\mathrm{III}^{49}$. El acuerdo alcanzado atrajo más apoyos a la causa del nuevo monarca y no pasó mucho tiempo antes de que se llegaran otras gentes de Extremadura ofreciéndole la fidelidad de sus concejos ${ }^{50}$.

Este sistema reveló pronto su debilidad, venía impuesto por unas circunstancias políticas y económicas complejas y se había adoptado con demasiada rapidez. No se habían estudiado con detenimiento algunas de las variables que lo definían como era el valor del oro mucho más cambiante que en tiempos precedentes al compás de la nueva y complicada situación que se venía dando en al-Ándalus y el imperio almohade. Tampoco se habían previsto los problemas que causaría la convivencia de múltiples acuñaciones de vellón indistinguibles unas de otras y con valores diferentes. El resultado inmediato fue la aparición de tipos de cambio extraoficiales pactados por los particulares.

En I2I9 encontramos el primer rechazo al cambio oficial. El arzobispo don Rodrigo Jiménez de Rada, intentó cancelar una deuda que tenía con la Orden de San Juan para lo cual aportaba 600 maravedís de oro y i.50o en dineros burgaleses,

\footnotetext{
momentos y manifestaba su extrañeza ante la posibilidad de que esta devaluación hubiera tenido lugar durante el efímero y complicado paso por la corona castellana de Enrique I o el turbulento comienzo de reinado de Fernando III (SÁnCHeZ-Albornoz, Claudio: op. cit., p. 611).

47. Historia de rebvs Hispaniae...VIIII,VII: «Verum quia perturbatione huiusmodi obsistente regales redditus ad stipendia defecerunt, et regina nobilis quicquid habuerat in largicionibus dispensarat, ad argenti et auri et gemmarum donario misit manum et queque ex talibus reseruarat in auxilium filii liberaliter erogauit,...».

48. Algún autor adelanta para finales de su reinado unos dineros burgaleses con un contenido de plata de $0,25-0,26$ g en sintonía con los presentes en nuestro cuadro (LADERo QUESADA, Miguel Ángel: «Monedas y políticas...», p. 143 y Fiscalidad y poder real en Castilla (1252-1369), Madrid, Real Academia de la Historia, 1993, p. 108).

49. Historia de rebvs Hispaniae...IX,v: «Cum autem audisset regina pociores Extremorum Dorii et de ultra serram Secobie conuenire, misit nuncios qui eis fidelitatis debitum suaderent. Cumque uiri Extremorum Dorii hoc audissent, uenire ad reginam nobilem continuo consenserunt, et cum ad Vallen Oleti comuniter conuenissent, ibidem tam Extremorum Dorii pocieres, qui pro omnibus uenerant, quam etiam magnates et milites Castellani comuni consensu regnum Castelle fidelitate debita regine nobili optulerunt».

50. Historia de rebvs Hispaniae...IX,vI: «Regina autem in regem filio sublimato, dum hec fierent, Palencie morabatur. Et ibi uenerunt ad eam ex Secobia et Abula et aliis oppidis Extremorum Dorii milites copiosi conciliorum suorum seruicia offerentes».
} 
contándose estos a 7,5 sueldos el maravedí. No estuvo de acuerdo la Orden con esta forma de pago, aceptando la moneda de oro, pero no el vellón. Se renegoció el acuerdo comprometiéndose el arzobispo a entregar I.200 maravedís de oro en el plazo de tres meses y reteniendo los sanjuanistas entretanto en concepto de prenda los maravedís de vellón, pero valorados en 8 sueldos y 8 dineros el maravedí. Hernández lo achaca a la permanencia en el circulante de tipos anteriores bastante devaluados ${ }^{5 \mathrm{y}} \mathrm{y}$ también habla de «la falta de confianza en la estabilidad» en la equivalencia oficial52. Probablemente en I2 I9 el cambio oro / plata sufría tensiones constantes al alza y la Orden no estaba dispuesta a perder ni un pepión, si el préstamo se hizo en oro, en oro se había de cancelar y si no ellos serían quienes impusieran la equivalencia con la moneda de vellón.

Según lo anterior el maravedí se cambiaba por I04 dineros lo que implicaría o bien un aumento del tipo de cambio del oro hasta $1: 7^{2} / 3$ o bien, suponiendo estable este, a una depreciación encubierta de los dineros que habrían pasado a tener solo o,216 g de plata. Incluso, una combinación de ambos factores en proporciones desconocidas. Trátese de cualquiera de las tres soluciones lo cierto es que hay una tendencia a todos los niveles y en todos los territorios peninsulares a soslayar los cambios oficiales y a negociar entre las partes implicadas uno propio para cada negocio.

\section{EL MARAVEDÍ ALFONSÍ NUEVO (B) Y LOS 90 DINEROS (1223-1268)}

\subsection{EL REINADO DE FERNANDO III}

Este ajuste fernandino no fue definitivo y hubo de completarse en I223, casi coincidente con el comienzo de su segundo septenio, para luego seguir un largo período en los que el sistema permaneció estable. El nuevo cambio se manifiesta documentalmente en los diplomas toledanos que desde finales de ese año introducen cláusulas que indican la aparición de un nuevo tipo de moneda de oro ${ }^{53}$. En noviembre se vendía una viña en la vega de Olías la Mayor, por un total de 30 mizcales de oro alfonsí «que hace correr ahora la ceca de Toledo»54. Cita equivalente aparece en marzo de I224 con motivo de la venta de otra viña, esta vez

1. HeRnÁndez, Francisco J.: Las rentas del rey..., p. CLV.

2. Idem, p. CLVI.

3. Oliva Manso, Gonzalo: op. cit., pp. 328-330.

54. González Palencia, Ángel: op. cit., vol. II, doc. 472 
situada en el pago de la Garganta, por precio de «7 mizcales de oro alfonsí, de los que ahora ha puesto en circulación la ceca» ${ }^{55}$.

Sin embargo, no existe a día de hoy ningún ejemplar de maravedí que puede relacionarse no sólo con esta emisión sino con cualquier otra posterior que pudiera haber realizado Fernando III siguiendo estos nuevos parámetros. Todesca no duda que éste acuñó moneda de oro, pero lo hizo siguiendo los patrones de sus antecesores $^{56}$. Su inmediato antecesor Enrique I ya había actuado de esta forma. Sus maravedís son prácticamente idénticos a los de Alfonso VIIl y de hecho incluso se mantuvo la inscripción «ALF» que recuerda a este primer rey que los acuñó. La única licencia que se permitieron los monederos enriqueños fue la inclusión de las fechas correspondientes a su reinado ${ }^{57}$.
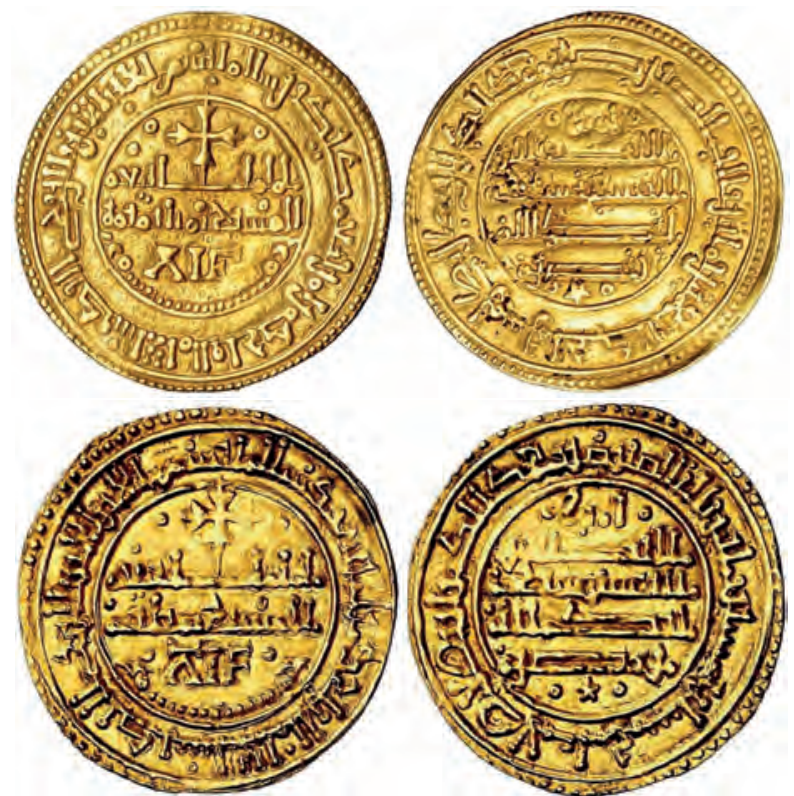

FIGURA 2. MARAVEDÍS ALFONSÍS NUEVOS (A) ACUÑADOS POR ALFONSO VIII (1193) Y ENRIQUE I (1217). Fuente: Jesús Vico y Heritage Auction.

El rey Santo continuaría utilizando los viejos cuños y ni siquiera procedería a la actualización de la fecha, de modo que no existe forma alguna de distinguir sus acuñaciones de las de sus antecesores. Beltrán, en cambio, discrepa y no cree

55. Idem, doc. 475

56. TODESCA, James J.: «The Monetary History...», p. 154.

57. En 2015 se subastó en Heritage Auctions un inédito maravedí acuñado en 1215 en el que Enrique I figura con su propio nombre «Henric»<https://coins.ha.com/itm/spain/world-coins/spain-castille-enrique-i-gold-morab-1253-safard-1215-ms64ngc-/a/3041-32396.s?ic4=ListView-Thumbnail-071515\#auction-info> [consultado el 04/11/2017]. Se han planteado dudas en lo que respecta a su autenticidad sin embargo en el estudio más completo hasta la fecha se considera auténtico (Mozo Monroy, Manuel: «Hipótesis sobre un morabetino de oro inédito de Enrique I de Castilla», Hécate, 2 (2015), pp. 147-174). 
que se tratara de monedas reales de oro; serían más bien monedas de cuenta de I8o dineros pepiones cada una aceptando para ello las menciones que se hacen en la documentación toledana de fracciones de mizcal o de sueldos como divisor del mismo ${ }^{58}$.

La presencia de esta esquiva moneda áurea estaría atestiguada en el siglo xIV en un texto catalán que reconoce la existencia de dos maravedís: «Item morabatins vells son a ley de XXI quirats, e als altres de XX quirats, e pesa lo dret moratabatí XXI quirats»59. De donde se identifica el maravedí alfonsí nuevo (A) como el morabatí vell o dret morabatí con una ley de $87,5 \%$ mientras el altre morabatí es el maravedí alfonsí nuevo (B) más moderno y de peor ley, un 80\%, y que sería una versión degenerada de su predecesor. Podemos observar que la fineza de estas monedas concuerda con la asignada ${ }^{60}$. Del maravedí alfonsí ya no quedaba rastro alguno por entonces.

En nuestra opinión parece claro que nos encontramos ante una moneda real de oro, pero con una particularidad que la hace destacar sobre otras emisiones de maravedís alfonsís, y es que en su condición de moneda de cuenta además de relacionarse con la moneda de vellón habitual -dineros burgaleses y pepiones-, también lo hace ahora con una nueva moneda, en esta ocasión de plata casi pura.

Se trata de unos dineros muy fuertes ya que quince de ellos valen un maravedí. En mayo de 1224 se vendió una casa cercana a la catedral toledana por «250 mizcales de oro alfonsí, de 15 dineros cada mizcal, que ahora hace correr la ceca de Toledo ${ }^{61} \gg$. En junio de ese mismo año la venta de una casa en el barrio de San Nicolás de Toledo se hizo en «38 mizcales de oro alfonsí, de la acuñación de Segovia, de los que cada mizcal vale $I_{5}$ dineros $^{62} \gg$. Estas citas a los nuevos dineros pueden entenderse de dos maneras. Bien interpretándolas como referencia a los dirhemes de buena plata almohade o más bien como la puesta en circulación de unos dineros «fuertes» y que se labrarían bajo parámetros muy semejantes sino idénticos que los dirhemes ${ }^{63}$. Los ejemplos contenidos en la documentación toledana son numerosos y se prolongan hasta enero de $1266^{64}$.

Queda aún un documento toledano más, fechado un poco antes, en diciembre de I223, y cuya traducción no está consensuada ${ }^{65}$. Se refiere a la venta de un mesón en el Arrabal de Francos, dentro de Toledo por «220 mizcales de oro alfonsí» al

\footnotetext{
58. Beltrán Villagrasa, Pío: «La gran dobla de Fernando el Santo», en Obra completa, vol. 2, Zaragoza, Universidad de Zaragoza, 1972, pp. 638-639.

59. Gual Camarena, Miguel: El primer manual hispánico de mercadería (siglo XIV), Barcelona, CSIC, 1981, p. 112.

60. Vid. supra nt. 9.

61. González PAlencia, Ángel: op. cit., vol. II, doc. 476

62. Idem, doc. 477

63. Francisco Olmos, José M. ${ }^{a}$ de: «El nacimiento de la moneda en Castilla. De la moneda prestada a la moneda propia», en I Jornadas Científica sobre Documentación jurídicoadministrativa, económico-financiera y judicial del reino castellano-leonés, siglos X-XIII, Madrid, Universidad Compluytense, 2002, p. 341).

64. González Palencia, Ángel: op. cit., vol. II y III, docs. 477, 483, 499b, 502, 506, 507, 511, ..., 1114

65. Idem, doc. 473 .
} 
decir de González Palencia y que Beltrán cambia de forma sustancial y lee «por precio cabal a número de ciento dos mizcales de oro alfonsí y veinte mizcales de plata» ${ }^{66}$. Estos últimos pudieran tratarse de los dineros de plata o de los burgaleses de vellón, cuestión compleja ante la falta de acuerdo entre los investigadores pero que era necesario comentar.

Su emisión se utilizaría en sus relaciones económicas con el mundo musulmán, tanto andalusí ${ }^{67}$ como norteafricano ${ }^{68}$. Era este un procedimiento habitual en las cecas del sur de Francia y norte de Italia donde se acuñaron imitaciones de dirhemes almohades, los denominados «millareses» al objeto de beneficiarse del diferente cambio oro/plata que existía entre estas zonas y el norte de África ${ }^{69}$. Con el tiempo no se consideró suficiente el beneficio obtenido y cada vez más se recurrió a lo largo del siglo XIII a la falsificación pura y dura de estas monedas reduciendo considerablemente la cantidad de plata presente en las mismas ${ }^{70}$. Son conocidos los diplomas de los reyes aragoneses por los que autorizan a distintas cecas de sus posesiones norpirenaicas la acuñación de estas monedas falsas a cambio de un subsidio económico a la monarquía ${ }^{71}$.

Más tarde tras las conquistas en Murcia y el Valle del Guadalquivir continuaron acuñándose estos dirhemes / mizcales / dineros de plata para garantizar la continuidad de la economía de estas regiones habitadas mayoritariamente en esos primeros momentos por musulmanes ${ }^{72}$. En Andalucía hallamos dos significativos ejemplos en los que se habla de monedas de plata, pero sin darles ningún valor. La primera cita aparece en el fuero de Segura de la Sierra de I246: «por que de cada año I dinero de plata y de peso y que los coia el almojarif por Sant Martin quando cogiere el almagrama para la Orden ${ }^{73}$. La segunda muestra es un documento sevillano de I25I por el que se concede a los genoveses el privilegio de establecerse en esta ciudad: «Et si jmplicauerint pecuniam suam in oleo debent soluere ratione portatici pro qualibet iarra unum denarium argenteum de Sibilla» ${ }^{74}$.

\footnotetext{
66. Beltrán Villagrasa, Pío: «Dos tesorillos...», p. 664.

67. Roma VALDÉs, Antonio: Moneda y sistemas monetarios..., pp. 147 y 169).

68. Rueda Sabater, Mercedes y SÁez Saiz, Inmaculada: «Hallazgos medievales de moneda castellana y leonesa», Numisma, 230 (1992), pp. 241-242, HeRnÁNDEZ, Francisco J.: Las rentas del rey..., p. CLXIII).

69. La mencionada escasez de oro se ve además amplificada por la entrada en los mercados mediterráneos de crecientes cantidades de metal argénteo -la «nueva plata»- procedentes de las cada vez más numerosas minas que se venían abriendo en Europa desde 1160 (SPUFFORD, Peter: op. cit., pp. 147-175).

70. SPUfFord, Peter: op. cit., p. 227-230; Riera Melis, Antoni: «Monedas y mercados en la Edad Media el Mediterráneo Noroccidental (c. 1190-1350)», en Moneda y monedas en la Europa medieval..., pp. 218-223; ARIZA ARMADA, Almudena: «El millarés. Revisión historiográfica», Revista numismática Hécate, 1 (2014), pp. 98-114.

71. Bотет i Sisó, Joaquim: Les monedes catalanes, vol. 2, Barcelona, Institut d'Estudis Catalans, Palau de la Diputació, 1909, pp. 52-61; RIERA Melis, Antoni: op. cit., pp. 219-221.

72. GIL FARRÉs, Octavio: Historia de la moneda..., p. 332.

73. Rodríguez Llopis, Miguel: «La evolución del poblamiento en las Sierras de Segura (Provincias de Albacete y Jaén) durante la Baja Edad Media», Al-Basit, 19 (1986), doc. 1.

74. GonzÁLEZ, Julio: Reinado y diplomas..., vol. III, doc. 823. Según una copia romanceada de 1337 se trata de una «meaja de plata de la moneda de Sevilla» (González Gallego, Ignacio: «El 'Libro de Privilegios de la nación genovesa'», Historia. Instituciones. Documentos, 1 (1974), doc. 2).
} 
La relación entre las dos nuevas monedas refleja la existencia de un alza en el valor del oro que vendría de antes como se intuía a la vista del documento de préstamo de I2I9 entre Jiménez de Rada y la Orden de San Juan y que nos daba un valor de 7 2/3. Este valor del oro se deduce también de las nuevas equivalencias constatadas:

Un dirhem $=$ Un dinero de plata $=\mathrm{I}, 543 \mathrm{~g}$ de plata

Un maravedí alfonsí nuevo $(\mathrm{B})=\mathrm{I} 5$ dirhemes $=$ I5 dineros de plata

3,II8 gramos de oro $=23, \mathrm{I} 45$ gramos de plata

Cambio oro $/$ plata $=7,42 \sim 71 / 2$

Que nos darían como resultado un nuevo sistema monetario:

Un maravedí alfonsí nuevo (B) = 3,II8 gramos de oro

Cambio oro $/$ plata $=7 \frac{1 / 2}{\text { a }}$

Un maravedí alfonsí nuevo $(B)=23,385$ gramos de plata

Un maravedí alfonsí nuevo $(B)=7,5$ sueldos $=90$ dineros

Un dinero $=0,26$ gramos de plata

Un marco de plata = Io maravedís de cuenta

Queda la duda de si Fernando Ill procedió a revaluar de forma paralela la moneda de vellón o la dejó con los parámetros de I2I7. Manteniendo las cosas como estaban se reportaba un beneficio oculto para las arcas reales pues el vellón debería de haberse labrado en adelante con un contenido en plata de 0,26 g. La ganancia inapreciable a primera vista -0,007 g por dinero- se volvía más sustancial cuando la trasladamos a la medida monetaria por excelencia como era el marco ${ }^{75}$. Sin embargo, como veremos un poco más adelante comparando el vellón portugués con el castellano sí tendríamos que aceptar la opción de un pequeño ajuste, al menos sobre el papel.

Otro punto que se constata al estudiar la documentación mozárabe toledana es que el «mizcal alfonsí de oro» mencionado de forma exclusiva hasta la aparición del «mizcal de oro alfonsí de I5 dineros» coexiste con éste hasta agosto de I225, pero desde esta fecha los documentos toledanos utilizan indistintamente una $u$ otra expresión dejando de lado el calificativo «de oro». ¿Cómo ha de entenderse esta desaparición de toda referencia al oro? Los problemas internos en que se debatía un Imperio almohade en franco retroceso reducirían su flujo monetario hacia Europa tanto por lo que respecta a la disminución de la actividad comercial en el Mediterráneo como a la interrupción de las pagas de los ejércitos que ya no están

75. La ganancia se elevaba a 2 sueldos o 24 dineros por marco de plata, 909 dineros de 0,253 g de plata si lo dejamos conforme a lo establecido en 1217 frente a 885 dineros de $0,26 \mathrm{~g}$ de plata si se hacía el ajuste. 
en la Península. Esta escasez de oro ha sido también señalada por Hernández ${ }^{76}$ tras constatar que las menciones de pagos en oro en las transacciones inmobiliarias son muy raras, pero lo achaca a la falta de confianza del cambio oficial oro / plata lo que provocaría a finales del reinado de Fernando Ill la retención por parte de los particulares de la moneda de oro que poseyeran. Efectivamente, ante la ausencia de oro africano y una política monetaria inmovilista que no adecúa la relación de cambio los particulares tienen dos opciones: la ocultación del oro limitando su uso a aquellas operaciones donde sea obligatorio y la introducción de las ya comentadas cláusulas privadas en sus contratos donde se establecía una relación entre el maravedí de cuenta y la moneda de vellón diferente a la oficial.

Esta ausencia de monetario almohade de oro y plata que antes corría con regularidad por estas regiones obligaría a una emisión limitada de maravedís devaluados y de una moneda de plata, remedo del dirhem ${ }^{77}$. Se estableció así un sistema basado en una moneda de oro de escasa circulación, el maravedí alfonsí nuevo (B), una moneda de plata denominada dinero de plata y una moneda de vellón, el dinero burgalés. y sus divisores, el pepión y la meaja ${ }^{78}$. Todos estos tipos monetarios estarían relacionados de la siguiente forma: I maravedí alfonsí nuevo (B) $\rightarrow$ I5 dineros de plata $\rightarrow 90$ dineros burgaleses $\rightarrow$ I8o pepiones $\rightarrow 360$ meajas.

Como unidades de cuenta estaban el sueldo, reunión de doce burgaleses o doce pepiones, y el mencal, equivalente a dieciocho pepiones ${ }^{79}$. Este sistema es el que funcionará durante casi todo el reinado de Fernando IIl y la mitad del de Alfonso $\mathrm{X}$. Las citas documentales al núcleo fundamental del sistema: maravedí -dinero burgalés- pepión son numerosas:

1221 (diciembre, 30): «IIII milia et DCC et VI aureos, partim in burgalensi, partim in pipionibus, partim in aoro, burgalensi computando VII solidos et dimidium pro aureo, de pipionibus XV solidos, in aureo uero CCC XXX IIII aureos» ${ }^{80}$.

1233 (noviembre, 24): «CCC maravedis XV sueldos de pepiones a maravedi o de Burgaleses VII sueldos et medio quales nos mas quisieredes» ${ }^{81}$.

1244 (octubre): «XXX morabedís burgaleses a VII solidos e medio el morabedí» ${ }^{82}$.

\footnotetext{
76. HeRnández, Francisco J.: Las rentas del rey..., p. CLXII.

77. Solución idéntica a la que llevó a cabo Alfonso VIII cuando se cortó el flujo de maravedíes andalusíes.

78. El rastro documental de estas monedas de vellón se constata por toda la Península (HERnÁndez, Francisco ).: Las rentas del rey..., pp. CLV-CLVI).

79. Crónica de Alfonso $X$, cap. I «Et las conpras pequennas fazíanlas a metales e a medios metales, que fazían diez e ocho pepiones el metal» (GonzÁlez Jıménez, Manuel: Crónica de Alfonso X: Según el Ms. II/2777 de la Biblioteca del Palacio Real (Madrid), Edición, transcripción y notas por...; Indice por M. ${ }^{a}$ Antonia Carmona RuIz, Murcia, 1999).

80. GARRIDo, José Manuel: Documentación de la catedral de Burgos (1184-1222), Burgos, Ediciones J. M. Garrido, 1983, doc. 533 .

81. GRASSOTTI, Hilda: «Don Rodrigo Ximénez de Rada, gran señor y hombre de negocios en la Castilla del siglo XIII», Cuadernos de Historia de España, 55-56 (1972), doc. vill.

82. Vignau y Ballester, Vicente: Indice de los documentos del Monasterio de Sahagún de la Orden de San Benito y glosario y diccionario geográfico de las voces sacadas de los mismos, Madrid, Aribau y Cía (Sucesores de Ribadeneyra), 1874, doc. 1903.
} 
1256: «moravedis alfonssis a quinze sueldos de pepiones el moravedi o a siete sueldos e medio de burgaleses el moravedi» ${ }^{83}$.

1265: «siete sueldos y medio de burgaleses cada maravedí» ${ }^{84}$.

1269 (agosto, 15): «dos mill morauedis alffonsis todos en dineros a quinze sueldos de pepiones cada morauedí» ${ }^{85}$.

Como vemos en las dos últimas citas, los burgaleses y pepiones siguieron utilizándose con habitualidad incluso después de la aparición de la moneda de la $\mathrm{I}^{\mathrm{a}}$ guerra. El Ordenamiento de Jerez los recoge en varios de sus capítulos (\#\# 9, ro, I8, 32, 33 ${ }^{86}$ y además del anterior documento sevillano hay otros murcianos que lo continúan citando en $1269^{87}$.

Las referencias al valor del maravedí aparte de reiterar la obligación de aplicar el cambio oficial sirven también para diferenciarlos de otras monedas áureas que como la mazmudina podrían correr por determinadas partes del reino y cuyo equivalente en moneda de vellón era inferior ( $133^{1 / 2}$ pepiones $)^{88}$. A pesar de esta reiteración persiste la negociación de tipos puntuales de cambio, no solo en los negocios particulares sino en cláusulas de derecho público como la presente en la carta-puebla de Torre de don Morant otorgada en I229 por Pedro González, Maestre de la Orden de Santiago. Aquí se establece un impuesto comunitario de Ioo maravedís alfonsís pagaderos en oro o, en su defecto, en moneda de vellón pero aplicando el cambio habitual existente en ese momento - «..., et estos LXX populatores fagan este foro, que pechen cada anno a la orden .C. morabetinos alfonsís, o dineros como andidiere el morabetino ${ }^{89}{ }^{89}$. Ocho años después vemos a Pedro Fernández de Azagra recibir un préstamo a cuatro años de Teobaldo I, rey de Navarra, por valor de «diez mil morabedís en oro Alfonsinos o los dineros que valiesen estos morabedís» ${ }^{\circ}$. Por esas mismas fechas en León, el fuero de Salamanca (\# 262) establecía de forma aún más clarificadora que «Quien dineros enprestar o mercado fezier o diere a ganancia assí commo andare esse día mo-

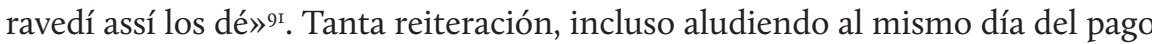
no puede interpretarse como una referencia al cambio oficial. La presencia de la coletilla solo puede referirse a un cambio paralelo que como se ve es ampliamente utilizado por todas las capas sociales y a lo largo de toda la Península.

83. Martín, José Luis: Documentos del archivo catedralicio de Zamora, Primera parte. 1128-1261, Salamanca, Universidad de Salamanca, 1982, doc. 156.

84. Martín Mínguez, Bernardino: Notas numismáticas, Madrid, Hijos de Nicolás Moya, 1916, p. 8.

85. Ballesteros Beretta, Antonio: Sevilla en el siglo XIII, Sevilla, Juan Pérez Torres, 1913, doc. 218.

86. Cortes de los antiguos reinos de León y de Castilla, vol. I, Madrid, Academia de la Historia, 1861, pp. 64-85.

87. Valls Taberner, Fernando: Los privilegios de Alfonso X a la ciudad de Murcia. Discurso inaugural del curso $1923-24$ en la Universidad de Murcia, Barcelona, Tipografía Católica Casals, 1923, doc. 28.

88. Valor sin referencia documental pero que se puede calcular relacionando esta moneda de oro con el maravedí alfonsí nuevo (B).

89. Rivera Garretas, Milagros: op. cit., doc. 155 .

90. BURRIEL, Andrés Marcos: Memorias para la del santo rey don Fernando III, dadas a luz con apéndices y otras ilustraciones, Madrid, Viuda de don Joaquín Ibarra, 1800, p. 440.

91. Martín, José Luis y CocA, Javier: Fuero de Salamanca, Salamanca, Diputación de Salamanca, 1987. 


\subsection{EL REINADO DE ALFONSO X}

El advenimiento de Alfonso X no supuso ninguna modificación importante en el sistema instaurado por su padre y así viene aceptándose por la historiografía más reciente que aleja los grandes cambios monetarios hasta mediados de la década de I26092. Incluso para algún autor ni siquiera se puede hablar de devaluación tras la emisión de la moneda de la primera guerra ${ }^{93}$. Así a pesar de todos los problemas que se venían acumulando Alfonso X no asumió las medidas necesarias, ignorando las señales del mercado y barriendo para debajo de la alfombra.

Este continuismo contrasta con las noticias que nos aparecen en la Crónica de Alfonso $X$, texto poco apreciado por la escasa rigurosidad del relato que hace de los primeros años de su gobierno ${ }^{94}$ pero que quizás haya que analizar nuevamente en lo que concierne a nuestro campo de estudio. Así lo han hecho con anterioridad algunos estudiosos que discrepan de esta opinión general y ven con extrañeza la posibilidad de unas confusiones que por situarse a comienzos del reinado estarían mejor referenciadas. Es el caso de León España que aporta en su favor una cita del Fuero Real (\# I,8,I) cuyas primeras concesiones datan de 255 y donde al establecerse el pago de las minutas a los escribanos públicos se evalúan en burgaleses ${ }^{95}$. Gautier, por su parte, acepta que apenas cuarenta años después de la muerte de Alfonso X se hubieran olvidado buena parte de los detalles de su política monetaria. No obstante, las citas de la crónica reflejarían el recuerdo que tenían en el momento de la redacción de la crónica, a comienzos del siglo XIV, de la existencia de una ruptura con las directrices monetarias del reinado de Fernando IIl, aunque sin poder precisarlas ${ }^{96}$.

La realidad es que el panorama monetario que se hace de Castilla es bastante confuso con algunas citas aparentemente contradictorias pero que creemos pueden encajarse. La primera de ellas incide en las bondades del sistema monetario

\footnotetext{
92. TOdesCA, James J.: «Money of account...», p. 281; TOdesCA, James J.: «The Monetary History...»; p. 160; GAUTIER DALCHÉ, Jean: «La politique monetaire...», pp. 83-85; HERNÁNDEZ, Francisco J.: Las rentas del rey..., p. CLXII-CLXIV. Una excepción notable es la Pellicer i Bru quien en un trabajo bastante reciente acepta todos los cambios monetarios reflejados en la crónica (PELLICER i BRU, Josep. Las acuñaciones y quiebras monetarias de Alfonso X y Sancho IV (12521284-1295), Barcelona, Asociación Numismática Española, 2008, pp. 20-31).

93. CASTÁN LANASPA, Guillermo: Política económica y poder político: moneda y fisco en el reinado de Alfonso X el Sabio, Valladolid, Junta de Castilla y León, 2000, pp. 40-52. Estas apreciaciones como toda la obra en general han sido contestadas con dureza por GAUTIER DALCHE, Jean: «La politique monetaire et fiscales d'Alphonse revisitée par Guillermo Castán Lanaspa», Alcanate, IV 2004-2005, pp. 315-352).

94. Las primeras críticas vertidas datan del siglo Xvill y fueron obra del Marqués de Mondéjar (Memorias del reinado del rey D. Alonso el Sabio, Madrid, Joachin Ibarra, 1777) a lo que habría que añadir la deficiente versión que se hizo del texto en la edición de Rosell basada en un manuscrito inadecuado para este objetivo (Crónicas de los Reyes de Castilla, vol. 1, Madrid, M. Ribadeneyra, 1875) y que ha sido puesto de relieve por Rodgers (Prolegomena to a Critical Edition of the "Cronica de Alfonso», Michigan, Ann Arbor, 1987). Un estudio de sus defectos a la vez que una justificación de su propia edición puede verse en GonzÁlez Jiménez, Manuel: Crónica de Alfonso X:..., pp. Ix y XIII y «Una nueva edición de la Crónica de Alfonso X», Cahiers de linguistique hispanique médiévale, 23 (2000), pp. 177-212 (doi : 10.3406/cehm.2000.918). 95. EspañA, León de: «El verdadero burgalés de la Crónica de Alfonso X», Gaceta Numismática, 149 (2003), pp. 61-62. 96. GAUTIER DALCHÉ, Jean: «Remarque sur les premières mutations monètaires d'Alphonse X de Castille», en Mélanges en honeur d'Etienne Fournial, Saint Etienne (Loire), 1978, p. 156.
} 
de Fernando Ill en el que la moneda de vellón es reconocida por su fortaleza y su casi perfecta alineación con la de oro de tal modo que la plata contenida en I8o pepiones de vellones venía a valer, con una pequeña diferencia, al oro contenido en un maravedí.

Et esta moneda era atán gruesa e de tantos dineros, que alcançaua a valer el marauedí tanto commo un marauedí de oro. Porque en aquel tienpo del rey don Ferrando corría en Castilla la moneda de los pepiones et en el reynado de León la moneda de los leoneses. E de aquellos pepiones valían çiento e ochenta el marauedíp7.

Pero esta cita choca frontalmente con otra presente unos capítulos después en la que al narrar lo acontecido en las Cortes de Sevilla (I28I) se alude a una moneda muy diferente que ha perdido una parte sustancial de su valor afectada por continuas depreciaciones encubiertas ${ }^{98}$ :

..., ca fallaua que las [sus] rentas todas que eran menguadas lo vno por el abatimiento de las monedas que fueron abatidas en el tienpo del rey don Ferrando, su padre, por el grand menester que ovo con los moros para las conquistas que fizo de los regnos de Seuilla e de Córdoua e de Jahén, et otrosy en el suyo por el grant menester que ovo en las conquistas que fizo en el regno de [Niebla e en el regno] de Murçia, et otrosí por la grant guerra que ovo con el rey Abén Yuçaf de Marruecos que pasó acá99.

Situación que se vuelve a comentar en la Crónica de Alfonso XI ${ }^{100}$ en el capítulo dedicado a las Cortes de Carrión (I3I2):

...; et otrosi por las monedas que avian abatidas muchas veces en tiempo del Rey Don Fernando, que ganó á Cordoba et á Sevilla, et en tiempo del Rey Don Alfonso su fijo; et en tiempo del Rey Don Sancho su fijo fué abatida una vez; et otra vez fué abatida en tiempo del Rey D. Fernando su fijo,...101.

Estas citas pueden considerarse válidas si las asociamos a dos mundos paralelos. La primera de ellas representa la versión oficial externalizada en los documentos y sostenida desde los entramados del poder castellano con una moneda de vellón fuerte y estable a lo largo del reinado a la que se reconoce una pequeña merma que podríamos identificar en la no regularización de i223. Allí, recordemos, se había producido el reajuste de la moneda de oro y no se había trasladado al vellón quedando con un contenido de $0,007 \mathrm{~g}$ de plata menos por moneda lo que justifica la expresión «que alcançaua a valer el marauedí tanto commo un marauedí de oro». Las siguientes referencias hacen alusión al mundo real, a los mercados y ferias de Castilla que utilizan una moneda en sus transacciones comerciales que ha perdido parte de su contenido en plata siguiendo el proceso iniciado ya en tiempos

97. Crónica de Alfonso X, cap. I.

98. Castán niega la existencia de estas devaluaciones fernandinas, al contrario, este habría comenzado en 1249 una política de moneda de buena ley (CASTÁN LANASPA, Guillermo: op. cit., p. 34).

99. Crónica de Alfonso X, cap. LXxv.

100. Las similitudes vienen de la común autoría de ambas obras por parte de Fernán Sánchez de Valladolid (GoNZÁLEZ JIMÉNEZ, Manuel: «Una nueva edición...», p. 182).

101. Cerdá y Rıco, Francisco (ed.): Crónica de d. Alfonso el Onceno, Madrid, Antonio de Sancha, 1787, cap. xIII. 
de Alfonso VIIl y que dio lugar a un incremento generalizado de los precios $^{\mathrm{I02}}$ que se acentuó a finales del reinado de Fernando III y comienzos de su sucesor.

El descontento generalizado movería a Alfonso X a tomar algunas medidas parciales buscando acallar las protestas sin atender al problema de fondo que era de origen puramente fiscal ${ }^{103}$. Aquí habría que situar las tasas de precios establecidas en $1252^{104}$ y $1256^{105}$ que intentaron sosegar una situación cada vez más desbocada y la noticia que nos habla de una sustitución de esos pepiones devaluados por otra moneda de vellón, los burgaleses ${ }^{106}$. Estos tendrían un valor oficial doble que los pepiones ya que noventa de ellos valían un maravedí y se supone que se emitirían bajo el supuesto de recuperar su auténtico valor, al que constantemente se alude en los diplomas oficiales ${ }^{107}$. Los sueldos pasaron ahora a contarse de una manera novedosa ya que no serían la reunión de doce monedas, sino solo de seis, en este caso burgaleses, aunque desde el punto de vista del poder adquisitivo no existía diferencia dado el carácter de múltiplo del burgalés sobre el pepión.

Et el rey don Alfonso, su fijo, en el comienço de su reynado mandó desfazer la moneda de los pipiones et fizo labrar la moneda de los burgaleses, que valía nouenta dineros el marauedí. E las conpras pequennas fazíanse a sueldos, et seys dineros de aquéllos valían un sueldo e quinze sueldos valía un marauedí108.

La cita anterior fechable en I252, primer año de su reinado, simplemente se limita a informarnos de la retirada de un tipo monetario y su sustitución por otro $^{\text {Io9 }}$, para nada nos descubre las razones que motivan este cambio y el objetivo político o económico que se pretende. Ni siquiera estamos ante una reforma

102. Crónica de Alfonso X, cap. I: «Et en este tienpo, por el mudamiento destas monedas, encaresçieron todas las cosas en los reynos de Castilla e de Leon e pujaron a muy grandes quantías».

103. Las campañas andaluzas culminadas con el largo asedio de Sevilla habían dejado una hacienda exhausta y a Alfonso $X$ con las manos atadas para actuar con libertad. Préstamos y anticipos varios unidos a una crisis económica y monetaria importante tuvieron que ser afrontados con una reforma impositiva importante pero los imprevistos limitaron su efectividad y se recurrió de una forma nunca antes vista a la manipulación monetaria.

104. Decretos económicos promulgados en las Cortes de Sevilla (1252): «Sepades que vi posturas que ficieron el Rey Don Alfonso mio Visabuelo, e el Rey don Fernando mio Padre a pro de ellos e de sos pueblos e de toda su tierra... e vos que me mostrastes los daños que recibiedes por que las posturas non se tenien asi como fueron dadas: et otrosi por que me mostrastes muchas veces los daños que recibiedes en las sobeianias que se facien, en las carestias grandes de las cosas que se vendien, ademas tobe por bien e por guisado de aquellas posturas que ellos ficieron...» (PROCTER, Evelyn S.: Curia y Cortes en Castilla y León. 1072-1295, Madrid, Cátedra, 1988, doc. IV).

105. Crónica de Alfonso X, cap. v: «... venieron a este rey don Alfonso muchas querellas de todas las partes de sus reynos que las cosas eran encaresçidas a tan grandes quantías que los omnes non las podían aver. Et por esto el rey puso los cotos, que es poner presçio a todas las cosas, cada vna qué quantía valiese».

106. Situación que se repitió durante la rebelión del infante Sancho con las reclamaciones de los burgueses en la reunión de Valladolid en abril de 1282 que se plasmaron en el ordenamiento de Cuéllar del mes siguiente donde se ordenó la emisión de burgaleses y pepiones supuestamente con el mismo valor de antaño. No fue así en la realidad y consta la resistencia a aceptar esta moneda en Burgos (Vid. González DíEZ, Emiliano: Colección diplomática del concejo de Burgos (884-1369), Burgos, Ayuntamiento de Burgos, 1984, docs. 118, 120, 121 y 122).

107. Castán reconoce su condición de moneda fuerte y su desaparición inmediata del mercado dejando su lugar en las transacciones a las monedas de peor calidad. Exactamente la misma situación que se vería unos años después con la aparición de la moneda de la guerra que barrió a su vez con los pepiones aún en circulación (CASTÁN LANASPA, Guillermo: op. cit., p. 44-45).

108. Crónica de Alfonso X, cap. I.

109. A todos los efectos una continuación de las emisiones anteriores de Fernando III (GAUTIER DaLché, Jean: «Remarques sur les premières...», p. 151). 
del sistema y menos aún frente a una mutación monetaria al estilo de las que se harán habituales en la segunda mitad del reinado. Cabe pensar en una emisión de burgaleses que intentara calmar el clima de descontento existente. Alfonso $\mathrm{X}$ se limitaría entonces a transformar sus reservas de plata, especialmente los pepiones de los que dispondría de una gran cantidad procedente de los tributos regios, en burgaleses mejores que los pepiones que sustituían pero que tampoco cumplirían los valores oficiales. Nos quedamos entonces a medio camino entre las dos tendencias señaladas al comienzo del capítulo, pero llevando la fecha más cerca de I256. En ese año tenemos una noticia de Colmenares ${ }^{\text {IIO }}$ donde afirma la existencia de una reunión de Cortes ${ }^{I I I}$ en la ciudad de Segovia en ese año donde las gentes acudieron a quejarse «del gouierno en baxa de moneda, y subida de precios ${ }^{\mathrm{II} 2}$. Tenemos también un documento asturiano dos años posterior por el que los concejos de Oviedo y Avilés se comprometían a implantar la moneda real - «devemos fazer tomar la moneda del rey en nuestras villas e en nuestras alfozes e en todo nuestro poderío»- estableciendo una multa de seis dineros a cualquiera que rehusara utilizar la susodicha moneda salvo que fuera falsa ${ }^{\mathrm{II}}$. A partir de este documento Gautier sostiene la existencia de una reciente emisión de una moneda que es claramente rechazada al considerarse desde un primer momento fraudulenta y claramente devaluada ${ }^{\mathrm{II} 4} \mathrm{y}$ que en nuestra opinión podrían identificarse con estos burgaleses que nominalmente valían dos pepiones, pero con un valor intrínseco más reducido.

Otra cuestión es el carácter que se le quiera dar a los denominados por Roma dineros pequeños alfonsís de uso habitual en algunas regiones de la corona y que gozarían según este autor de una estimable pervivencia al mantenerse circulando en Andalucía hasta I270 y en Galicia incluso a comienzos del siglo XIV ${ }^{115}$. Castán rechaza su existencia ante la escasez de referencias documentales, una sola y enfrentada al resto que además puede explicarse por un fallo en su lectura. En defensa de su posible realidad solo puede argumentarse su condición de moneda fraccionaria alineada en el sistema junto a pepiones y burgaleses de los que podría tratarse de su divisor más pequeño, por tanto, una pujesa ${ }^{\mathrm{II} 6}$.

\footnotetext{
110. Noticia aceptada por Colmeiro (Cortes de los antiguos reinos de León y de Castilla. Introducción. Parte primera, Madrid, Academia de la Historia, 1883, p. 155) pero rechazada por Marichalar y Manrique (Historia de la legislación y recitaciones del derecho civil de España, vol. 3, Madrid, Imprenta Nacional, 1862, pp. 79-81).

111. Al decir de O'Callaghan, una simple reunión de representantes de las ciudades de Castilla y la Extremadura (O'Callaghan, Joseph F.: El rey sabio, el reinado de Alfonso X de Castilla, Sevilla, Universidad de Sevilla. Secretariado de Publicaciones, 1999, p. 213).

112. Colmenares, Diego de: Historia de la insigne ciudad de Segovia y compendio de las historias de Castilla, Madrid, Diego Díez, 1637, cap. XXII,V.

113. Sanz Fuentes, M. ${ }^{a}$ Josefa, Álvarez Castrillón, José A. y Calleja Puerto, Miguel: Colección diplomática del Concejo de Avilés en la Edad Media (1155-1498), Avilés, Universidad de Oviedo, 2011, doc. 9.

114. Gautier DalchÉ, Jean: «La politique monetaire d'Alphonse X», Cuadernos de Historia de España, 69 (1987), pp. 84-85.

115. Ballesteros BeretTa, Antonio: Sevilla en el siglo XIII, doc. 120

116. CaStÁn LANASPA, Guillermo: op. cit., pp. 41 y $45-46$.
} 
Sin embargo, para encontrar elementos de más interés y que reflejen la realidad monetaria del momento hay que salir fuera de la corona castellano-leonesa y utilizar el Ordenamiento portugués de precios y posturas de i253. En el apartado correspondiente a la moneda se dice que:

In primis marcha argenti ualeat duodecim libram monete portugalensis. Et denarius legionensis ualeat tres denarios portugalensis. Et uncia de auro ualeat undecim libras portugalenses monete. Et denarius burgalensis ualeat tres denarius et medaculam portugalenses. Et denarius turonensis ualeat quatuor denarios et medaculum portugalenses. Et morabitinus nouus de auro ualeat uiginti et duos solidos. Et morabitinus uetus ualeat uiginti et septem solidos. Et quadratus de auro ualeat quadraginta et quinque solidos. Et morabitinus alfonsinus triginta solidos ${ }^{117}$.

De donde podemos calcular el valor del oro en ese momento ${ }^{\mathrm{II} 8}$ :

Un marco de plata = I2 libras (de cuenta $)=240$ sueldos de vellón

Un maravedí alfonsí nuevo (B) = 30 sueldos de vellón

Un marco de plata $=8$ maravedís alfonsís nuevos $(\mathrm{B})$

$230,0465 \mathrm{~g}$ de plata $=8 \cdot 3, \mathrm{II} 8 \mathrm{~g}$ de oro

Cambio oro $/$ plata $=9,222 \sim 9^{1 / 4^{119}}$

Y con este valor del oro deducimos el sistema de equivalencias que teóricamente debía regir el sistema monetario castellano del momento:

Un maravedí alfonsí nuevo (B) = 3,II8 g de oro

Cambio oro $/$ plata $=9^{1 / 4}$

Un maravedí alfonsí nuevo $(\mathrm{B})=28,842 \mathrm{~g}$ de plata

Un maravedí alfonsí nuevo $(\mathrm{B})=7,5$ sueldos $=90$ dineros

Un dinero $=0,32$ gramos de plata

Un marco de plata $=8$ maravedís de cuenta

Sin embargo, esto no concuerda con el valor asignado oficialmente a la moneda castellana en ese mismo texto:

Un maravedí alfonsí nuevo $(B)=30$ sueldos de dineros portugueses

\footnotetext{
117. Teixeira de Aragão, Augusto C.: Descripção geral e historica das moedas cunhadas en nome dos Reis, Regentes e Governadores de Portugal, vol. I, Lisboa, Imprensa Nacional, 1847, doc. 3.

Para la identificación de los maravedís citados vid. Oliva Manso, Gonzalo: op. cit., pp. 330 y 333-334.

118. Podemos añadir también un nuevo dato que en su momento dejó de lado Beltrán: «No interesa de momento averiguar de qué libra o marco fue la onza de oro citada en el texto» («Dos tesorillos...», p. 659). Según el texto:

Una onza de oro $=11$ libras de dineros portugueses $=220$ sueldos

Una dobla de oro $=45$ sueldos

Una onza de oro $=5$ doblas de oro $=23,39$ gramos de oro

1 libra romana $=327,15 \mathrm{~g}=14$ onzas

119. Cifra muy cercana a las que da Ladero, quien considera que la plata estaba cara en estos primeros años del reinado de Alfonso X, oscilando su ratio con el oro entre 9,13 y 9,20 (LADERO QUESADA, Miguel Ángel: «Monedas y políticas...», pp. 144).
} 
Un dinero burgalés $=3,25$ dineros portugueses

Un maravedí alfonsí nuevo $(B)=9$,23I sueldos = III dineros burgaleses

Un maravedí alfonsí nuevo $(B)=3, \mathrm{II} 8 \mathrm{~g}$ de oro $=28,842 \mathrm{~g}$ de plata

I dinero burgalés $=0,26 \mathrm{~g}$ de plata

Cantidad esta última que es exacta a la calculada para el dinero burgalés tras la aparición del maravedí alfonsí nuevo (B) en I223 y el reajuste consiguiente en el sistema monetario. Analizando este Ordenamiento comprobamos el desajuste tremendo existente en el sistema con una distorsión absoluta entre todos los valores monetarios hasta el punto de que pueden deducirse tres sistemas diferentes.

El primero de todos ellos, ficticio, es el que debería de haber regido si se quería mantener una absoluta correlación entre los valores del oro y la plata y estaría basado en un dinero con o,32 g de plata. El segundo de ellos era el oficial, venía impuesto por la autoridad real desde su posición de poder y obligaba a todos los agentes sociales a utilizarlo en sus negocios económicos. En virtud de este sistema la moneda de vellón contenía o,26 g de plata y 90 de ellos equivalían al maravedí alfonsí nuevo (B). El tercer y último modelo monetario es el efectivamente existente y que venía dado por las decisiones unilaterales del rey que ante los problemas que se le iban planteando en cada momento reaccionaba con una quita en el contenido de plata de las monedas dejándolas por debajo de los 0,26 g de plata oficiales. El resultado no podía ser otro que el rechazo frontal de las gentes a esta situación con el consiguiente incremento de precios y el establecimiento de cláusulas específicas en los contratos entre particulares donde se reflejaban tipos de cambio en constante variación.

Igualmente continuó acuñándose moneda de plata, también devaluada respecto a su predecesora como se deduce de la venta en I254 de unas heredades en Masquerra, donde los intervinientes en la compra pactaron un tipo de cambio diferente al oficial. El precio fue de «XX mrs. bonos alfonsís contados en dineros a diz e siete sobre cada mr. ${ }^{120}$. Si vemos estas $\mathrm{I} 7$ piezas conteniendo I,35 $\mathrm{g}$ de plata $^{\mathrm{I21}}$ vienen a equivaler a I5 monedas con I,543 g de plata. Con el nombre más preciso de «dineros de plata» aparecen en el Fuero Real (\# 4,I2,7), cuya primera promulgación data de I255, así como en la documentación tributaria de Murcia ${ }^{\mathrm{I22}}$. Estos ejemplos unidos a los que hemos vistos del área andaluza nos indicarían la persistencia de determinadas figuras impositivas de origen andalusí que pervivieron bajo la

\footnotetext{
120. Martínez, Eduardo: Colección diplomática del Real Convento de Santo Domingo de Caleruega (Burgos), Vergara, El Rosario, 1931, doc. ccxviII.

121. Este valor aparece citado en HERNÁNDEZ, Francisco J.: Las rentas del rey..., p. CLXIII.

122. 1257, julio, 11: «...quitóles et franqueóles a todos los christianos que y fueren vezinos et moradores et touieren y las casas maiores pobladas assi como so fuero manda, el dinero de plata que me solien dar por razón de las espuertas de los figos et de las passas» (Torres Fontes, Juan: Documentos de Alfonso X, Murcia, Real Academia Alfonso X el Sabio, 2008, doc. LXXIII); 1260, junio, 29: «Et otrossi, uos quitamos los cinco dineros de plata que dauades en Murcia por cada ciento por razón de la truiamania» (Idem, doc. LXXXVII.)
} 
dominación castellana incluso en lo que respecta a sus cuotas ${ }^{\mathrm{I2}}$. Esta circulación restringida, tanto en lo que se refiere a su uso como a su área de circulación, explicaría la escasez de ejemplares conservados.

Esta complicada situación económica y monetaria del reino castellano-leonés se fue enredando aún más con factores exógenos derivados de las decisiones dinásticas y políticas de Alfonso $\mathrm{X}^{\mathrm{I24}}$. En primer lugar, tenemos el conocido como «Fecho del Imperio», expresión con la que se alude a su candidatura a la corona del Sacro Imperio apoyada en su condición de hijo de Beatriz de Suabia, perteneciente a la casa de Hohenstaufen que había venido rigiendo los destinos de esa entidad con algunas breves interrupciones desde hacía más de un siglo.

La Crónica de Alfonso $X$ narra la llegada en 1256 de una primera embajada y la favorable acogida a sus propuestas recibiendo una primera remesa de dinero con la que ir sondeando el clima político italiano - «dióles muy grand algo de lo suyo e enbiólos»-. La cosa no quedó ahí pues previendo los desembolsos futuros consiguió de sus súbditos que hasta tanto no acabara el asunto «que le diesen cada anno dos seruiçios, demás de los pechos e rentas que le auían a dar» ${ }^{125}$. Tamaño incremento impositivo no debió ser bien visto a medida que transcurrían los años y no se alcanzaba a vislumbrar una pronta finalización. Al tratar los desórdenes de I272-I273 la crónica ${ }^{126}$ habla ya de un único servicio anual que además tenía fecha de caducidad para I276. Incluso el rey granadino se vio obligado en I273 a hacer un pago extraordinario de 250.000 maravedís ${ }^{127}$ además de verse hostigado continuamente con demandas para que adelantase las parias del año siguiente $^{\mathrm{I2} 8}$. La narración anterior se hace más contundente en la obra de Loaysa donde se habla de gasto desorbitados - «expensas fere incredibilis»- motivados por la prodigalidad del rey con sus partidarios dando como resultado obligado el incremento desmesurado de los impuestos, unos extraordinarios y otros novedosos - «propter quo necesario habuit ab hominibus terre sue servicia postulare et eisdem collectas imponere insuetas» $-{ }^{\mathrm{I2} 9}$.

Estas ambiciones personales de Alfonso X supusieron una sangría considerable de las arcas reales. Ríos de dinero corrieron hacia Europa, primero para pagar los

\footnotetext{
123. Los impuestos en cuestión muestran a las claras su raigambre musulmana en sus propios nombres: almagrana y trujamania, o en el tipo de productos que graban: aceite, higos y pasas, más propios del sur peninsular y, al menos en un primer momento, afectaban a todos los residentes para luego como recogen los documentos murcianos ir eximiendo a los pobladores cristianos. Una mejoría clara de sus condiciones de vida en busca de un flujo sostenido de emigrantes que atenuara la abrumadora proporción de población musulmana.

124. O'CALLAGHAN, Joseph F.: «Paths to ruin: The Economic and Financial Policies of Alfonso the Learned», en BuRNS, Robert I. (ed.): The Worlds of Alfonso the Learned and James the Conqueror. Intellect and Force in the Middle Ages, Princeton, Princeton University Press, 1985, pp. 41-67.

125. Crónica de Alfonso X, cap. XVIII.

126. Idem, cap. XLVIII.

127. Idem, cap. XLIX.

128. Idem, cap. LV.

129. LOAYSA, Jofré de: Crónica de los reyes de Castilla, edición, introducción y notas de Antonio García MARTínez, Murcia, Academia Alfonso X el Sabio, 1982, cap. 7.
} 
apoyos que consiguieron su nombramiento como emperador del Sacro Imperio en I257, luego descendió el caudal, pero continuó la salida de metales preciosos para sostener una ficción cada vez más debilitada que se prolongó hasta I275. Además, había que sumar los gastos ocasionados por el viaje realizado a Beaucaire en I274, tanto los propios del rey como las donaciones que hizo a los nobles y clérigos que debían acompañarle ${ }^{\mathrm{r3}}$.

Entre las dos fechas anteriores el sistema acabó saltando por los aires. El detonante fue un asunto interno que apareció de manera un tanto inesperada. En la primavera de 1264 los mudéjares residentes en el Valle del Guadalquivir y Murcia se alzaron en armas, aliados con el monarca nazarí Muhammad I. La situación se volvió sumamente compleja y durante un año la Frontera estuvo en peligro. La firma de una tregua con el sultán granadino en la primavera del año siguiente permitió controlar la situación en Andalucía, pero en Murcia se necesitó incluso la inestimable ayuda de Jaime 1 , suegro del rey castellano, demorándose su pacificación hasta comienzos de $1266^{131}$. Esta secuencia de acontecimientos admitida por la mayoría de los autores debería matizarse según O’Callaghan ${ }^{132}$ para quien la caída de Jerez, último reducto de importancia en Andalucía, se demoró hasta octubre de i266 lo que supondría aún mayores necesidades de recursos para el rey.

El enorme esfuerzo financiero acompañado del cese temporal de las parias granadinas que no volvieron a pagarse hasta I269 obligó a recurrir a medidas ya conocidas, pero en un grado nunca visto. Uno de los expedientes utilizados por Alfonso X para proveerse de fondos fue la emisión de la conocida como moneda de la $\mathrm{I}^{\mathrm{a}}$ guerra de Granada, aunque también puede encontrarse citada en los documentos como alfonsíes, de la guerra, blanca o blanquillas. Al nuevo dinero de referencia se le atribuyó el mismo valor que el burgalés aun cuando su contenido en plata desde el primer momento era inferior al oficial ${ }^{133}$. Tras unos primeros años complicados hubo de dejarse de lado el modelo seguido desde I2I7 y empezar desde cero. Las Cortes celebradas en Jerez en I268 fueron el marco donde se institucionalizó el cambio que supuso el fin del maravedí de oro y su conversión a una moneda de cuenta pura y dura. Por su parte la dobla pasó a ser la moneda de oro de referencia. No podía ser de otra manera, la acuñación de maravedís desapareció durante el reinado de su padre y el numerario de oro en circulación estaba compuesto mayoritariamente por doblas, las cada vez más escasas almohades y,

130. Crónica de Alfonso X, cap. LV.

131. Ballesteros Beretta, Antonio: Alfonso X el Sabio, Madrid-Barcelona, Salvat, 1963, pp. 362-403; GonzÁlez Jiménez, Manuel: Alfonso X el Sabio, Barcelona, Ariel, 2004, pp. 173-197; MARTínez SAnTAmARTA, H. Salvador: Alfonso X, el Sabio: una biografía, Madrid, Polifemo, 2003, pp. 179-190, García SANJuÁn, Alejandro: «Causas inmediatas y alcance de la revuelta mudéjar de 1264", Mudéjares y moriscos, cambios sociales y culturales (Actas del XI Simposio Internacional de mudejarismo: Teruel 12-14 septiembre de 2002), Teruel, Centro de Estudios Mudéjares, 2004, pp. 505-518.

132. O'Callaghan, Joseph F.: El Rey Sabio..., pp. 225-234.

133. El incremento de la presión fiscal también implementado aseguraba una estabilidad de ingresos a largo plazo, pero tardaba en dar resultados, mientras que los beneficios de la devaluación eran inmediatos, apenas puestas en circulación las nuevas monedas (LADERO QUESADA, Miguel Ángel: «Monedas y políticas...», p. 145). 
sobre todo, las nazaríes que afluían con relativa abundancia a través de las parias debidas al reino castellano. No paso mucho tiempo antes de que el mismo Alfonso $\mathrm{X}$ emitiera sus propias doblas ${ }^{\mathrm{1} 34}$.

Las normas establecidas en las cortes jerezanas intentaron marcar unas reglas precisas que pretendían garantizar una moneda de vellón estable, aunque de escaso valor, pero al menos ya reconocido y correctamente situado en el modelo monetario respecto al maravedí de cuenta. La historia demostró al poco que se trataba de un simple espejismo y apenas dos años después apareció el dinero prieto, moneda con un notable contenido de plata, pero desvirtuada por un valor irreal en relación al maravedí de cuenta y que supuso un nuevo golpe a la economía. Según el ordenamiento de estas cortes:

\footnotetext{
$1^{\circ}$ La moneda de los dineros alfonsís, que yo mandé facer después que comencé la guerra que la confirmase para en todos mis días e que la non creciese nin menguase, nin en la ley nin en (la) talla que agora es. Et yo touelo por bien et otorgolo que sea así.

$2^{\circ}$ La dobla del oro vala tres mrs. Et el mr. de oro alfonsí dos mrs., el marco de plata fina quel den en la moneda por quince mrs...
}

El sistema monetario de equivalencias que se deduce de este segundo punto es el siguiente:

Una dobla $=4,626 \mathrm{~g}$ de oro

Cambio oro $/$ plata $=$ Io

Un maravedí de cuenta $=15,336 \mathrm{~g}$ de plata

Un maravedí de cuenta $=7,5$ sueldos $=90$ dineros

Un dinero $=0,17$ gramos de plata ${ }^{135}$.

Un marco de plata = I5 maravedís de cuenta

La única relación que no se encuentra en el documento jerezano es la composición entre el maravedí de cuenta y los dineros, pero puede rastrearse en numerosos textos contemporáneos y posteriores. En I272 en la zona segoviana se habla de los «moravedis de los annos de la guerra que es el moravedi siete solidos et medio et diçenlos alfonssis» ${ }^{136}$ y un año después en Oviedo nos aparecen estas

\footnotetext{
134. No existe unanimidad respecto a la emisión de doblas por Fernando III al no existir ninguna moneda que pueda atribuírsele. En base a un documento portugués de 1280 Beltrán afirma su realidad y Farrés y Rueda le secundan. Más recientemente otros autores como España y Roma manifiestan ciertas dudas. Vid.: BELTRÁN VILLAGRASA, Pío: «La gran dobla...», pp. 632-645; GIL FARRÉs, Octavio: Historia de la moneda..., p. 328; RuedA, Mercedes: Primeras acuñaciones de Castilla y León, Valladolid, Junta de Castilla y León, 1991, pp. 24, 30, 47 y 95; Romá VALDÉs, Antonio: Moneda y sistemas monetarios..., pp. 166 y 189; España, León de: Sistemas monetarios..., p. 148.

135. Esta cantidad es aceptada por numerosos autores LADERO QUESADA, Miguel Ángel: «Monedas y políticas...», p. 147; CASTÁn LANASPA, Guillermo: op. cit., p. 47; HeRnÁndez, Francisco J.: Las rentas del rey..., p. CLXVIII, nt. 102) y se aproxima a la media (0,181 gr.) de los cuatro ejemplos analizados por Todesca («The Monetary History...», p. 197). 136. Villar García, Luis M.: Documentación medieval de la catedral de Segovia 1115-1300, Salamanca, Universidad de Salamanca, 1991, doc. 185 .
} 
mismas monedas adaptadas a los patrones leoneses: «XX morabetinos de bonos dineros enbranquidos elos quales dineros foron fechos en tiempo de la guerra, ye yo soe bien pagado por cunto de VIll soldos cada un morabetin» ${ }^{137}$.

Este nuevo dinero suponía, al menos sobre el papel, una pérdida de $0,089 \mathrm{~g}$ de plata respecto al valor oficial de $0,26 \mathrm{~g}$ constatado en el ordenamiento portugués de $1253^{\mathrm{I} 38}$. Sobre esta pieza de referencia se articularía un sistema completo, la conocida por los numismáticos como moneda de seis líneas, con dos divisores de la mitad y de un cuarto -meajas y pujesas ${ }^{139}$, como en otras ocasiones anteriores, aunque no las encontremos citadas con este nombre-. En este contexto habría que insertar dos múltiplos: uno del doble, los llamados «buenos dineros» ${ }^{140}$ y el otro, un dinero de plata de I,35 g de plata, por tanto, un óctuplo en línea con otros semejantes ya comentados ${ }^{\mathrm{I4}}$.

\section{CONCLUSIONES}

Con la emisión en II72 de los maravedís alfonsís la monarquía dio solución al problema planteado con la escasez de numerario áureo a la vez que pasó a controlar la política monetaria en todos sus ámbitos haciendo de ella uno de los principales instrumentos para intervenir en la economía y la hacienda castellana. Las alteraciones en la ley de la moneda se fueron convirtiendo en una constante, desestabilizando la economía castellana y mostrando el camino a las grandes quiebras de Alfonso X. Estas decisiones de política interna unidas a otra procedente del exterior y no controlable como fue la disminución constante del flujo de oro andalusí trajo consigo una sostenida revalorización del oro frente a la plata lo que se tradujo en términos monetarios a un incremento constante del número de dineros de vellón que se hacían necesarios para intercambiar por un maravedí de plata.

137. Fernández Conde, Francisco J., Torrente Fernández, Isabel y Noval Menéndez, Guadalupe de la: El monasterio de San Pelayo de Oviedo, Historia y fuentes. I: colección diplomática (996-1325), Oviedo, Monasterio de San Pelayo, 1978, docs. 132 .

138. Para Castán no cabría hablar de devaluación, simplemente estaríamos ante la emisión de una meaja «perfectamente alineada» con los pepiones y dineros y con un valor de un cuarto de estos últimos (CASTÁN LANASPA, Guillermo: op. cit., pp. 49-50).

139. El contenido de plata de esta pujesa sería entonces de $0,0425 \mathrm{~g}$ y casi coincidiría con el atribuido en su momento por Pío Beltrán y admitido por otros autores que daban al dinero alfonsí un valor de solo o,0435 g (BELTRÁN VILLAGRASA, Pío: «Dos tesorillos...», p. 676; Collantes VIDAL, Esteban: «Notas sobre las monedas de Alfonso X», Acta Numismática, 6 (1976), p. 151). Algunos autores sostienen que pudieron acuñarse incluso por debajo hasta 0,0345 g (ROMÁ VALDÉs, Antonio: "La rebelión del infante don Sancho y su incidencia en las acuñaciones del siglo XIII en León y Castilla», Nvmisma, 239 (1997), p. 77; LADERO QUESADA, Miguel Ángel: «La hacienda real castellana en el siglo XIII», Alcanate: Revista de estudios alfonsíes, 3 (2002-2003), pp. 229 y 233).

140. BRAÑA PASTOR, José Luis y Romá VALDÉS, Antonio: «La moneda de seis líneas de Alfonso X de Castilla y León», Nvmisma, 243 (1999), p. 34.

141. Fontella Ballesta, Salvador: «El hallazgo numismático de la finca 'La Pita' (Alhama de Murcia)», Gaceta Numismática, 84 (1987), pp. 47-56; BRAÑA PASTOR, José Luis y Romá VALDÉs, Antonio: «La moneda ...», pp. $26-28$. 


\begin{tabular}{|c|c|c|c|c|c|}
\hline & $1172-1187$ & $1187-1217$ & $1217-1223$ & $1223-1268$ & $1268-\ldots$ \\
\hline \multirow{3}{*}{$\begin{array}{l}\text { Moneda de oro } \\
\text { (g de oro) }\end{array}$} & Maravedí & Maravedí alfonsí & í Maravedí alfonsí & Maravedí alfonsí & \multirow{3}{*}{$\begin{array}{l}\text { Dobla } \\
4,626\end{array}$} \\
\hline & alfonsí & nuevo $(A)$ & nuevo $(A)$ & nuevo (B) & \\
\hline & 3,84 & 3,411 & 3,411 & 3,118 & \\
\hline $\begin{array}{l}\text { Cambio } \\
\text { oro / plata }\end{array}$ & $62 / 3$ & $62 / 3$ & $62 / 3$ & $7^{1 / 2}$ & 10 \\
\hline $\begin{array}{l}\text { Maravedí de } \\
\text { cuenta } \\
\text { (g de plata) }\end{array}$ & 25,6 & 22,738 & 22,738 & 23,385 & 15,336 \\
\hline $\begin{array}{l}\text { Maravedí } \\
\text { de cuenta }\end{array}$ & $\begin{array}{l}5 \text { sueldos = } \\
60 \text { dineros }\end{array}$ & $\begin{array}{l}5 \text { sueldos = } \\
60 \text { dineros }\end{array}$ & $\begin{array}{l}7^{1 / 2} \text { sueldos = } \\
90 \text { dineros }\end{array}$ & $\begin{array}{l}7^{1 / 2} \text { sueldos }= \\
90 \text { dineros }\end{array}$ & $\begin{array}{l}71 / 2 \text { sueldos = } \\
90 \text { dineros }\end{array}$ \\
\hline $\begin{array}{l}\text { Dinero } \\
\text { (g de plata) }\end{array}$ & 0,427 & 0,379 & 0,253 & 0,26 & 0,17 \\
\hline Marco de plata & $\begin{array}{l}9 \text { maravedís de } \\
\text { cuenta }\end{array}$ & $\begin{array}{l}10 \text { 1/4 maravedís } \\
\text { de cuenta }\end{array}$ & $\begin{array}{l}10 \text { 1/4 maravedís } \\
\text { de cuenta }\end{array}$ & $\begin{array}{l}10 \text { maravedís } \\
\text { de cuenta }\end{array}$ & $\begin{array}{l}15 \text { maravedís } \\
\text { de cuenta }\end{array}$ \\
\hline
\end{tabular}

A tenor de todo lo dicho en las páginas anteriores las intervenciones en la política monetaria podrían clasificarse en tres categorías diferenciadas por su impacto en la economía y la publicidad con la que se dan a conocer. Las primeras de ellas afectan al maravedí, son por ello detectables con cierta facilidad y al trasladarse a la moneda de vellón alteran sustancialmente todos los círculos económicos. Por su importancia estaban respaldadas por un previo acuerdo de Cortes o poco posterior. También de conocimiento público son las alteraciones oficiales de la moneda de vellón que no implican modificaciones en la de oro. La mayoría de las veces asociadas a una necesidad perentoria de recursos. En las restantes ocasiones esta devaluación de la moneda de vellón puede ser también la constatación oficial de una situación que viene de antes convirtiéndose entonces en el punto final de un proceso de sucesivas devaluaciones unilaterales y subrepticias llevadas a cabo por la monarquía. Estas modificaciones ocultas serán las más habituales por las dificultades para detectarse y formarían la última categoría. No dejan rastros directos en la documentación, pero pueden deducirse a través de las fuentes escritas y numismáticas ${ }^{\mathrm{I} 42}$.

\footnotetext{
142. A finales del siglo XIII y tras el caos en que se sumió el reino con las continuas y extremas decisiones monetarias las fuentes historiográficas empiezan a introducir estas cuestiones en sus relatos. Al principio apenas una mención a la emisión -«mandó labrar una moneda á sus señales, que llamaron coronados»- (Crónica de Sancho IV, cap. III, p. 73 en Crónicas de los Reyes de Castilla, vol. 1), para ir aumentando en los detalles que la motivaron (Crónica de Fernando IV, cap. III, p. 110) y también sus consecuencias (Crónica de Alfonso XI, cap. XCVIII).
} 
La emisión de moneda de vellón con bajo contenido en plata, el pepión y su meaja más adelante las blancas de la primera guerra y sus divisores, tendría como finalidad fomentar el uso de la moneda en las pequeñas transacciones engañando al consumidor pues a menores cantidades de metal precioso más complicado se haría comprobar la merma establecida. De esta manera el blanqueo superficial que se les daba a las blancas tenía como objetivo evitar su rechazo por la población al constatarse ya a primera vista su escasez de plata ${ }^{\mathrm{I} 43}$.

La posibilidad de sustraerse a estos manejos regios era complicada. Para la gente menuda los métodos existentes para verificar la calidad de la moneda como eran el ensaye por piedra de toque $\mathrm{I}^{\mathrm{I} 44} \mathrm{o}$ la copelación les exigían unos conocimientos y una instrumentación que no estaba al alcance de todos ${ }^{145}$. En los grandes negocios en los que se movían cantidades ingentes de moneda no quedaba otra solución que hacer una selección aleatoria de dineros, efectuar la media con los resultados obtenidos y calcular el cambio consiguiente. Algo así debió de efectuarse en el préstamo que hizo en I2 I9 la Orden de San Juan al arzobispo Rodrigo Jiménez de Rada.

Nos encontramos así ante un período movido donde se ensayan soluciones que se desplegarán más adelante con todo su potencial y que harán de Castilla en la Baja Edad Media el mejor ejemplo de cómo no utilizar las políticas monetarias en sustitución de las fiscales como medio para cubrir las necesidades de la hacienda real.

\footnotetext{
143. HeRnÁndez, Francisco J.: Las rentas del rey..., p. CLXVII.

144. TORRES LÁZARO, Julio: «La fabricación de la moneda en la Edad Media», XI Congreso Nacional de Numismática. Zaragoza, 16-19 de Octubre de 2002, Zaragoza, Real Casa de la Moneda. Fábrica Nacional de Moneda y Timbre, 2003, pp. 180-181. 145. En las cecas valencianas el personal especializado disponía de juegos de 62 puntas de oro (MATEU y LLOPIS, Felipe: «El vocabulari medieval de l'exercici de la monederia segons documents valencians», Butlletí de Dialectologia Catalana, 24 (1936), doc. v).
} 


\section{BIBLIOGRAFÍA}

Ariza Armada, Almudena: «El millarés. Revisión historiográfica», Revista numismática Hécate, I (20I4), pp. 98-II4.

Ballesteros Beretta, Antonio: Sevilla en el siglo XIII, Sevilla, Juan Pérez Torres, I9I3.

Ballesteros Beretta, Antonio: Alfonso X el Sabio, Madrid-Barcelona, Salvat, I963.

Beltrán Villagrasa, Pío: «La gran dobla de Fernando el Santo», en Obra completa, vol. 2, Zaragoza, Universidad de Zaragoza, I972, pp. 632-645.

Beltrán VILlagrasa, Pío: «Dos tesorillos de vellones ocultos en la primera época del reinado de Alfonso X», en Obra completa, vol. 2, Zaragoza, Universidad de Zaragoza, I972, pp. 646-698.

Bотет i Sısó, Joaquim: Les monedes catalanes, 3 vols., Barcelona, Institut d'Estudis Catalans, Palau de la Diputació, I909.

Braña Pastor, José Luis y Roma Valdés, Antonio: «La moneda de seis líneas de Alfonso X de Castilla y León», Nvmisma, 243 (I999), pp. 25-50.

BurRiel, Andrés Marcos: Memorias para la del santo rey don Fernando III, dadas a luz con apéndices y otras ilustraciones, Madrid, Viuda de don Joaquín Ibarra, I8oo.

CASTÁN LANASPA, Guillermo: Política económica y poder político: moneda y fisco en el reinado de Alfonso X el Sabio, Valladolid, Junta de Castilla y León, 2000.

Cerdé y Rico, Francisco (ed.): Crónica de d. Alfonso el Onceno, Madrid, Antonio de Sancha, I787.

Charlo Brea, Luis (ed.): Crónica latina de los Reyes de Castilla, Cádiz, Universidad de Cádiz, I984,

Collantes Vidal, Esteban: «Monedas de Alfonso VIIl y sus problemas», Acta Numismática, 3 (I973), pp. II3-I36.

Collantes Vidal, Esteban: «Notas sobre las monedas de Alfonso X», Acta Numismática, 6 (I976), pp. I4I-I66.

Colmenares, Diego de: Historia de la insigne ciudad de Segovia y compendio de las historias de Castilla, Madrid, Diego Díez, I637.

Cortes de los antiguos reinos de León y de Castilla, 7 vols., Madrid, Real Academia de la Historia, I86I-I884.

ESPAÑA, León de: Sistemas monetarios peninsulares. La acuñación de moneda cristiana tras la invasión de los musulmanes hasta el siglo XV, Madrid, Fundación León de España, 2002.

EspañA, León de: «El verdadero burgalés de la Crónica de Alfonso X», Gaceta Numismática, I49 (2003), pp. 57-62.

Fernández Conde, Francisco J., Torrente Fernández, Isabel y Noval Menéndez, Guadalupe de la: El monasterio de San Pelayo de Oviedo, Historia y fuentes. I: colección diplomática (996-I325), Oviedo, Monasterio de San Pelayo, I978.

Flórez, Enrique (ed.): «Anales Toledanos» II, España Sagrada, vol. XXIIl, Madrid, Imprenta de D. Gabriel Ramírez, I767, pp. 40I-409.

Fontella Ballesta, Salvador: «El hallazgo numismático de la finca 'La Pita' (Alhama de Murcia)», Gaceta Numismática, 84 (1987), pp. 47-56.

Francisco Olmos, José María de: «El maravedí de oro de Alfonso VIII: un mensaje cristiano escrito en árabe», Revista General de Información y Documentación, 8.I (I998), pp. 283-30I.

Francisco Olmos, José M. ${ }^{a}$ de: «El nacimiento de la moneda en Castilla. De la moneda prestada a la moneda propia», I Jornadas Científica sobre Documentación jurídicoadministrativa, económico-financiera y judicial del reino castellano-leonés, siglos $X$-XIII, Madrid, Universidad Compluytense, 2002, pp. 303-346. 
GARcía López, Juan Catalina: La Alcarria en los dos primeros siglos de su reconquista. Discursos leídos ante la Real Academia de la Historia en la recepción del Excmo. Sr. D... en 27 de mayo de I894, Madrid, El Progreso, I894.

GARCíA SANJUÁn, Alejandro: «Causas inmediatas y alcance de la revuelta mudéjar de I264», Mudéjares y moriscos, cambios sociales y culturales (Actas del XI Simposio Internacional de mudejarismo: Teruel I2-I4 septiembre de 2002), Teruel, Centro de Estudios Mudéjares, 2004, pp. 505-518.

GARrido, José Manuel: Documentación de la catedral de Burgos (II84-I222), Burgos, Ediciones J. M. Garrido, 1983.

GAUTIER DALChÉ, Jean: «L'histoire monétaire de l'Espagne septentrionale et centrale du IX au XIl siècles quelques réflexions sur divers problèmes», Anuario de Estudios Medievales, 6 (1969), pp. 43-96.

GaUtier DalchÉ, Jean: «Remarque sur les premières mutations monètaires d'Alphonse $\mathrm{X}$ de Castille», en Mélanges en honeur d'Etienne Fournial, Saint Etienne (Loire), I978, pp. I47-I56.

GaUtier Dalché, Jean: «La politique monetaire d'Alphonse X», Cuadernos de Historia de España, 69 (1987), pp. 77-95.

Gautier Dalché Jean: «Le rôle de la reconquête de Tolède dans l'histoire monetaire de la Castille (I085-II74)», en Estudios sobre Alfonso VI y la reconquista de Toledo. Actas del II Congreso Internacional de Estudios Mozárabes (Toledo, 20-26 Mayo 1985), vol. II, Toledo, Instituto de Estudios Visigótico-Mozárabes, I988, pp. II-25.

GAUTIER DALChÉ, Jean: «La politique monetaire et fiscale d'Alphonse revisitée par Guillermo Castán Lanaspa», Alcanate, IV 2004-2005, pp. 315-352.

Gil FARRÉs, Octavio: Historia de la moneda española, Madrid, Diana, I959.

GonZÁLEZ, Julio: Alfonso IX, Madrid, CSIC. Instituto Jerónimo Zurita, I944.

GonZÁlez, Julio: El Reino de Castilla en la época de Alfonso VIII, 2 vols., Madrid, I96o.

GonZÁlez, Julio: Reinado y diplomas de Fernando III, 3 vols., Córdoba, Publicaciones del Monte de Piedad y Caja de Ahorros de Córdoba, I983.

GonZÁlez DíEz, Emiliano: Colección diplomática del concejo de Burgos (884-I369), Burgos, Ayuntamiento de Burgos, I984.

González Gallego, Ignacio: «El 'Libro de Privilegios de la nación genovesa'», Historia. Instituciones. Documentos, I (I974), pp. 275-358.

González Jiménez, Manuel: Crónica de Alfonso X: Según el Ms. II/2777 de la Biblioteca del Palacio Real (Madrid), Edición, transcripción y notas por...; Índice por M. ${ }^{\mathrm{a}}$ Antonia CARMona Ruiz, Murcia, I999.

GonZÁlez JIMÉnez, Manuel: «Una nueva edición de la Crónica de Alfonso X», Cahiers de linguistique hispanique médiévale, 23 (2000), pp. I77-2I2 (doi : 10.3406/cehm.2000.918).

González JiméneZ, Manuel: Alfonso X el Sabio, Barcelona, Ariel, 2004.

GonZález PAlencia, Ángel: Los mozárabes de Toledo en los siglos XII y XIII, 4 vols., Madrid, Instituto de Valencia de Don Juan, I928-I930.

Grassottı, Hilda: «Don Rodrigo Ximénez de Rada, gran señor y hombre de negocios en la Castilla del siglo XIIl», Cuadernos de Historia de España, 55-56 (I972), pp. I-302.

Grassottr, Hilda: «Sobre la moneda de Castilla en la época de don Rodrigo Jiménez de Rada», en Miscelánea de estudios sobre instituciones castellano-leonesas, Bilbao, Nájera, I978, pp. 423-43I.

Gual Camarena, Miguel: El primer manual hispánico de mercadería (siglo xIV), Barcelona, CSIC, I98I. 
Hernández, Francisco J.: «Las Cortes de Toledo de i207», Las Cortes de Castilla y León en la Edad Media: actas de la primera etapa del Congreso Científico sobre la Historia de las Cortes de Castilla y León, Burgos 30 de septiembre a 3 de octubre de 1986, vol. I, Valladolid, Cortes de Castilla y León, I988, pp. 219-266.

HeRnández, Francisco J.: Las rentas del rey. Sociedad y fisco en el reino castellano del siglo XIII, Madrid, Fundación Ramón Areces, 1993.

Iвrahim, Tawfiq: «Ponderales andalusíes», Nvmisma, 233 (I993), pp. 39-68.

JimÉnez de RADA, Rodrigo: Historia de rebvs Hispaniae sive Historia gothica, Turnhout, Brepols Publishers, 2010.

LAdERo QuesadA, Miguel Ángel: Fiscalidad y poder real en Castilla (I252-I369), Madrid, Real Academia de la Historia, I993.

LADERo QueSADA, Miguel Ángel: «Monedas y políticas monetarias en la Corona de Castilla (siglos XIII a XV)», Moneda y monedas en la Europa medieval (siglos XII-XV): XXVI Semana de Estudios Medievales, Estella, I9 a 23 de julio de 1999, Pamplona, Gobierno de Navarra, 2000, pp. I29-I78.

LAdero QUeSADA, Miguel Ángel: «La hacienda real castellana en el siglo XIII», Alcanate: Revista de estudios alfonsíes, 3 (2002-2003), pp. 229 y 233.

LOAYSA, Jofré de: Crónica de los reyes de Castilla, edición, introducción y notas de Antonio García Martínez, Murcia, Academia Alfonso X el Sabio, I982, cap. 7.

Loscertales de García de Valdeavellano, Pilar: Tumbos del Monasterio de Sobrado de los Monjes, 9 vols., Madrid, Dirección General del Patrimonio Artístico y Cultural, Archivo Histórico Nacional, 1976.

Marichalar, Amalio y Manrique, Cayetano: Historia de la legislación y recitaciones del derecho civil de España, 9 vols., Madrid, Imprenta Nacional, I86I-I872.

Martín, José Luis: Documentos del archivo catedralicio de Zamora, Primera parte. II28-I26I, Salamanca, Universidad de Salamanca, I982.

Martín, José Luis y CocA, Javier: Fuero de Salamanca, Salamanca, Diputación de Salamanca, I987. Martín Mínguez, Bernardino: Notas numismáticas, Madrid, Hijos de Nicolás Moya, I9I6.

Martínez, Eduardo: Colección diplomática del Real Convento de Santo Domingo de Caleruega (Burgos), Vergara, El Rosario, I93I.

Martínez Santamarta, H. Salvador: Alfonso X, el Sabio: una biografía, Madrid, Polifemo, 2003.

MAteu y Llopis, Felipe: «El vocabulari medieval de l'exercici de la monederia segons documents valencians», Butlletí de Dialectologia Catalana, 24 (1936), pp. 98-I26.

Medina Gómez, Antonio: Monedas hispano-musulmanas, Toledo, Instituto Provincial de Investigaciones y Estudios Toledanos, I992.

MenÉndez PidAl, Ramón (ed.): Primera Crónica General, Madrid, Bailly-Bailliere é Hijos, I9o6.

Mondéjar, Marqués de: Memorias del reinado del rey D. Alonso el Sabio, Madrid, Joachin Ibarra, I777.

Moxó Ortiz de Villajos, Salvador: «Ėpoca de Alfonso X» en Jover Zamora, José M. ${ }^{a}$ (dir.): Historia de España, vol. xııı, Madrid, Espasa Calpe, I990.

Mozo Monroy, Manuel: «Hipótesis sobre un morabetino de oro inédito de Enrique I de Castilla», Hécate, 2 (2015), pp. I47-I74

O'Callaghan, Joseph F.: «Paths to ruin: The Economic and Financial Policies of Alfonso the Learned», en Burns, Robert I. (ed.): The Worlds of Alfonso the Learned and James the Conqueror. Intellect and Force in the Middle Ages, Princeton, Princeton University Press, I985, pp. 4I-67. 
O'CALlaghan, Joseph F.: El rey sabio, el reinado de Alfonso X de Castilla, Sevilla, Universidad de Sevilla, Secretariado de Publicaciones, I999.

Oliva Manso, Gonzalo: «Enigmas monetarios en el derecho local. Los mencales y maravedís en los fueros castellanos», Revista General de Información y Documentación, 26-I (2016), pp. 313-340.

Pellicer i BRU, Josep: Las acuñaciones y quiebras monetarias de Alfonso X y Sancho IV (I252I284-I295), Barcelona, Asociación Numismática Española, 2008.

Pérez Rodríguez, Francisco Javier: Os documentos do Tombo de Toxos Outos, Santiago de Compostela, Consello da Cultura Galega, Sección de Patrimonio Histórico, 2004.

Procter, Evelyn S.: Curia y Cortes en Castilla y León. 1072-I295, Madrid, Cátedra, I988.

Riera Melis, Antoni: «Monedas y mercados en la Edad Media el Mediterráneo Noroccidental (c. II90-I350)», en Moneda y monedas en la Europa medieval..., pp. 193-256.

Rivera Garretas, Milagros: La encomienda, el priorato y la villa de Uclés en la Edad Media (II74-I3IO). Formación de un señorío de la Orden de Santiago, Madrid-Barcelona, CSIC, I985.

Rodgers, Paula K: Prolegomena to a Critical Edition of the «Cronica de Alfonso», Michigan, Ann Arbor, 1987.

Rodríguez Llopis, Miguel: «La evolución del poblamiento en las Sierras de Segura (Provincias de Albacete y Jaén) durante la Baja Edad Media», Al-Basit, I9 (I986), 5-32.

Roma Valdés, Antonio: «La rebelión del infante don Sancho y su incidencia en las acuñaciones del siglo XIII en León y Castilla», Nvmisma, 239 (I997), pp. 75-90.

Roma VAlDÉs, Antonio: Moneda y sistemas monetarios en Castilla y en León durante la Edad Media (I087-I366), Barcelona, Asociación Numismática Española, 2000.

Roma VAlDÉs, Antonio: Composición metálica de las monedas leonesas y castellanas de la Edad Media, Santiago de Compostela, A. Roma, 20 Io.

Rosell, Cayetano: Crónicas de los Reyes de Castilla, 3 vols., Madrid, M. Ribadeneyra, I875-I878.

Rueda, Mercedes: Primeras acuñaciones de Castilla y León, Valladolid, Junta de Castilla y León, I99I.

Rueda Sabater, Mercedes y Sáez Saiz, Inmaculada: «Hallazgos medievales de moneda castellana y leonesa», Nvmisma, 230 (1992), pp. 205-260.

Sainte-Marthe, Denis de: Gallia Christiana, in provincias ecclesiasticas distributa: qua series et historia Archiepiscoporum, episcoporum et abbatum Franciae vicinarumque ditionum..., I6 vols., París, J-B Coignard, I7I5-I865.

SÁNChEZ-Albornoz, Claudio: «¿Devaluación monetaria en León y Castilla: al filo del I200?», en Homenaje a Jaime Vicens Vives, vol. I, Barcelona, Universidad de Barcelona, Facultad de Filosofía y Letras, I965, pp. 607-617.

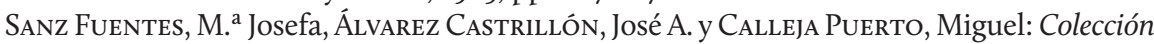
diplomática del Concejo de Avilés en la Edad Media (II55-I498), Avilés, Universidad de Oviedo, 20II.

SPUFFORD, Peter: Dinero y moneda en la Europa medieval, Barcelona, Crítica, I99I.

TeiXeira de Aragão, Augusto C.: Descripção geral e historica das moedas cunhadas en nome dos Reis, Regentes e Governadores de Portugal, 3 vols., Lisboa, Imprensa Nacional, I847.

Todesca, James J.: «Money of account and circulating coins in Castile-Leon c. I085-I300», Problems of Medieval Coinage in the Iberian Area, 3 (I988), pp. 27I-286.

Todesca, James J.: «The Monetary History of Castile-Leon (ca. IIoo-I300) on light of the Bourgey hoard», American Numismatic Society Museum Notes, 33 (I988), pp. I29-203.

Torres Fontes, Juan: Documentos de Fernando IV, Murcia, Academia Alfonso X el SabioCSIC, I980. 
Torres Fontes, Juan: Documentos de Alfonso X, Murcia, Real Academia Alfonso X el Sabio, 2008.

Torres LÁzaro, Julio: «La fabricación de la moneda en la Edad Media», XI Congreso Nacional de Numismática. Zaragoza, I6-I9 de Octubre de 2002, Zaragoza, Real Casa de la Moneda. Fábrica Nacional de Moneda y Timbre, 2003.

Valls Taberner, Fernando: Los privilegios de Alfonso X a la ciudad de Murcia. Discurso inaugural del curso I923-24 en la Universidad de Murcia, Barcelona, Tipografía Católica Casals, I923.

VAllvé Bermejo, Joaquín: «Notas de metrología hispano-árabe. III. Pesos y monedas», Al-Qantara, 5 (I984), pp. I47-I68.

Veas Arteseros, Francisco de Asís: Documentos de Alfonso XI, Murcia, Academia Alfonso $\mathrm{X}$ el Sabio-CSIC, I997.

Vignau y Ballester, Vicente: Índice de los documentos del Monasterio de Sahagún de la Orden de San Benito y glosario y diccionario geográfico de las voces sacadas de los mismos, Madrid, Aribau y Cía (Sucesores de Ribadeneyra), i874.

Villar García, Luis M.: Documentación medieval de la catedral de Segovia III5-I30o, Salamanca, Universidad de Salamanca, I99I. 

Calidad de Revistas

científicas Españolas

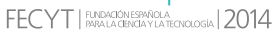

SERIE III HISTORIA MEDIEVAL

REVISTA DE LA FACULTAD DE GEOGRAFÍA E HISTORIA
AÑO 2018

ISSN: 0214-9745

E-ISSN 2340-1362

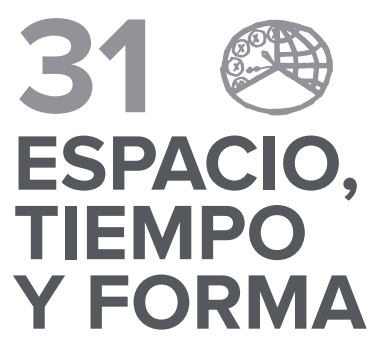

GREGoRIO DEL SER QUIJANO

Carmelo Luis López, In Memoriam

\section{Artículos · Articles}

29 SOHA ABBOUd Haggar

Un resumen del tratado jurídico de Al-Tafrí: el Manuscrito Árabe 1233 del Monasterio de El Escorial y su supuesta relación con Leyes de Moros

EDUARDo Aznar VALLejo

Norma y conflicto en la navegación castellana bajomedieval

69 Carlos Barquero Goñ

Transferencias de recursos de la Orden de San Juan desde España hasta el Mediterráneo Oriental durante la Edad Media

\section{Margarita Cabrera Sánchez}

La muerte del príncipe Don Juan. Exequias y duelo en Córdoba y Sevilla durante el otoño de 1497

\section{Francisco de Paula Cañas Gálvez}

Primogenitura, continuidad dinástica y legitimitad instituciona en Castilla a principios del siglo XV: Catalina de Trastámara, Princesa de Asturias (1422-†1424)

\section{Paloma Cuenca Muñoz}

El códice visigótico de los Moralia in lob, ms. lat. 83 de la John Rylands Library de Manchester

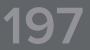

\section{JOSÉ MARÍA DIAGO JIMÉNEZ}

Las instituciones educativas de carácter religioso en el reino hispanovisigodo de los siglos VI y VII a través de los cánones conciliares y las reglas monásticas

MARÍA Díez Yáñez

La Ética aristotélica en Castilla: las bibliotecas universitarias medievales y prerrenacentistas

\section{Estefanía Ferrer del Río}

Rodrigo de Mendoza, I Marqués del Cenete y I Conde del Cid: paralelismos entre su biografía y su pretendida genealogía

\section{ALEJANDRo García Morilla \\ Escritura publicitaria de transición: entre la visigótica y la carolina.} El paradigma burgalés

María Dolores García Oliva

Señores contra campesinos: un conflicto por la tierra en Mirabel a finales de la Edad Media y principios de los Tiempos Modernos (1488-c. 1520)
34.3 jaime García Carpintero lópez de Mota

La hospitalidad santiaguista a finales de la Edad Media: el proyecto de reconstrucción del hospital de Alarcón

377 LAURA DA GRACIA

La posesión agraria individual en los registros notariales de Fuente el Sol (1481-1482

4.03 Mauricio Herrero Jiménez

El valor de los documentos reales en los procesos de la Real Chancillería de Valladolid

431 Miguel José López-Guadalupe Pallarés

Procesos de señorialización en los concejos de la Extremadura castellano-leonesa. Un estado de la cuestión

455 Ángel Martínez Catalán

Las rentas decimales del cabildo catedralicio de Cuenca a inicios del siglo XV (1400-1432)

4.83 Gonzalo Oliva Manso

Cien años de moneda en Castilla (1172-1268). El siglo del maravedí de oro

521 jesús Olivet García-Dorado

El cabildo de curas y beneficiados de Toledo en la segunda mitad del siglo XV. Composición y aspectos institucionales (1455-1488)

547 Mariel PÉrez

Clérigos rurales, comunidades y formación de las estructuras parroquiales en la diócesis de León (siglos XI-XIII)

575 Milagros Plaza Pedroche

La Orden de Calatrava en la Baja Edad Media (1350-1500): repaso historiográfico

597 Pedro Andrés Porras Arboledas

La pervivencia del Fuero de Cuenca en los inicios de la Modernidad: el testimonio de los fueros de Consuegra y Requena

619 Juan Pablo Rubio Sadia

Los mozárabes frente al rito romano: balance historiográfico de una relación polémica

SANDRA SUÁREZ GARCíA

Los habices de la Vega de Granada como forma de conocimiento del reino nazarí y su transformación tras la conquista: la alquería de La Zubia 


\section{1}

\section{ESPACIO,}

\section{TIEMPO}

\section{Y FORMA}

SERIE III HISTORIA MEDIEVAL

REVISTA DE LA FACULTAD DE GEOGRAFÍA E HISTORIA

\section{De medievalistas ilustres · On Renowned Medievalists}

671 Francisco Abad Nebot

Entradas para un Diccionario

\section{Libros $\cdot$ Books}

679 Almagro Vidal, Clara, Paisajes medievales en el Campo de Calatrava (CARLos BARQUero GoÑI)

681 Carvajal Castro, Álvaro, Bajo la máscara del Regnum. La monarquía asturleonesa en León (854-1037) (JOSÉ MANUEL RODRÍGUEZ GARCíA)

683 Fuente Pérez, María Jesús, Violante de Aragón, reina de Castilla (ANA ECHEVARRía ARsuaga)

687 Martín Prieto, Pablo, Historia del pensamiento medieval: filosofia y teología (FRANCISCO LEÓN FLORIDO)

689 Pardo de Guevara y Valdés, Eduardo (ed.), Mujeres con poder en la Galiciamedieval (siglos XIII-XV). Estudios, biografías y documentos (ENRIQUe CANTERA MONTENEGRO)

693 Ríos Saloma, Martín (ed.), El mundo de los conquistadores (Jessica Ramírez MéndeZ)

690 Solórzano Telechea, Jesús, Arízaga Bolumburu, Beatriz y BOCHACA, Michel (eds.), Las sociedades portuarias de la Europa atlántica en la Edad Media (ANTONIO ORTEGA VILLOSLADA)

703 VAL VALDIVIEso, María Isabel del (coord.), El agua en el
imaginario medieval. Los reinos ibéricos en la Baja Edad Media (MARÍA Jesús Fuente)

707 Villar García, Luis Miguel, Archivo Municipal de Segovia. Documentación medieval, 1166-1474 (ENRIQUE CANTERA MONTENEGRO) 